\title{
Guía de recomendaciones para el manejo perioperatorio de pacientes con infección por SARS-CoV-2 (COVID-19)
}

\section{Practical guidelines for the anesthesia management of patients with SARS-CoV-2 infection (COVID-19)}

Editores: Acad. Dr. Raúl Carrillo-Esper,* Dr. Gabriel E Mejía-Terrazas*

Dr. Víctor Manuel Acosta-Nava, ${ }^{1}$ Dra. María del Rocío A Alcántara-Muñoz, ${ }^{2}$ Dra. Alma Dolores Arenas-Venegas, ${ }^{3}$ Mtra. en Psic. Adriana Carapia-Sadurni, ${ }^{4}$ Dr. Jorge Raúl Carrillo-Córdoba, ${ }^{5}$ Acad. Dr. Raúl Carrillo-Esper, ${ }^{6}$ Dra. Idoris Cordero-Escobar, ${ }^{7}$ Dr. Luis Felipe Cuellar-Guzmán, ${ }^{8}$ Dra. Dania Elena Escamilla-Ríos, ${ }^{9}$ Dra. Diana América Fernández-Martínez, ${ }^{10}$ Dra. Luz Gabriela Franco-Padilla, ${ }^{8}$ Dr. Miguel Ángel García-Lara, ${ }^{11}$ Dra. Ana Lilia Garduño-López, ${ }^{1}$ Dr. Ricardo Eli Guido-Guerra, ${ }^{1}$ Dr. José Adolfo Islas-Velasco, ${ }^{5}$ Dra. Nora Lorena López-León, ${ }^{12}$ Dr. Gabriel Mancera-Elías, ${ }^{13}$ Dra. Ruth Martínez-Isarraraz, ${ }^{14}$ Dra. Nélida Mayorga-Castillo, ${ }^{8}$ Dra. Leslian Janet Mejía-Gómez, ${ }^{15}$ Dr. Gabriel E Mejía-Terrazas, ${ }^{16}$ Dra. Cecilia Úrsula Mendoza-Popoca, ${ }^{17}$ Dra. María Alejandra Minakata-Quiroga, ${ }^{9}$ Dra. Delia Brenda Paola Ocampo-Valencia, ${ }^{18}$

Dra. Maricruz Pérezamador-del Cueto, ${ }^{8}$ Dra. Dolores Pérez-Pérez, ${ }^{19}$ Dr. Juan Manuel Portela-Ortiz, ${ }^{18}$ Dr. Mario Suárez-Morales, ${ }^{17}$

Dr. Manuel Alejandro Vázquez-Flores, ${ }^{20}$ Dra. Elvia Gabriela Villars-Zamora ${ }^{8}$
Anestesiología

Julio-Septiembre 2020

Vol. 43. No. 3. pp 182-213

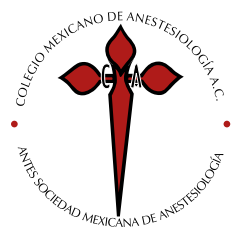

* Editores.

Solicitud de sobretiros: Acad. Dr. Raúl Carrillo-Esper Colegio Mexicano de Anestesiología, A.C.

Revista Mexicana de Anestesiología. E-mail:

revistacmx@revistacomexane.com

Recibido para publicación: 20-04-2020

Aceptado para publicación: 09-10-2020

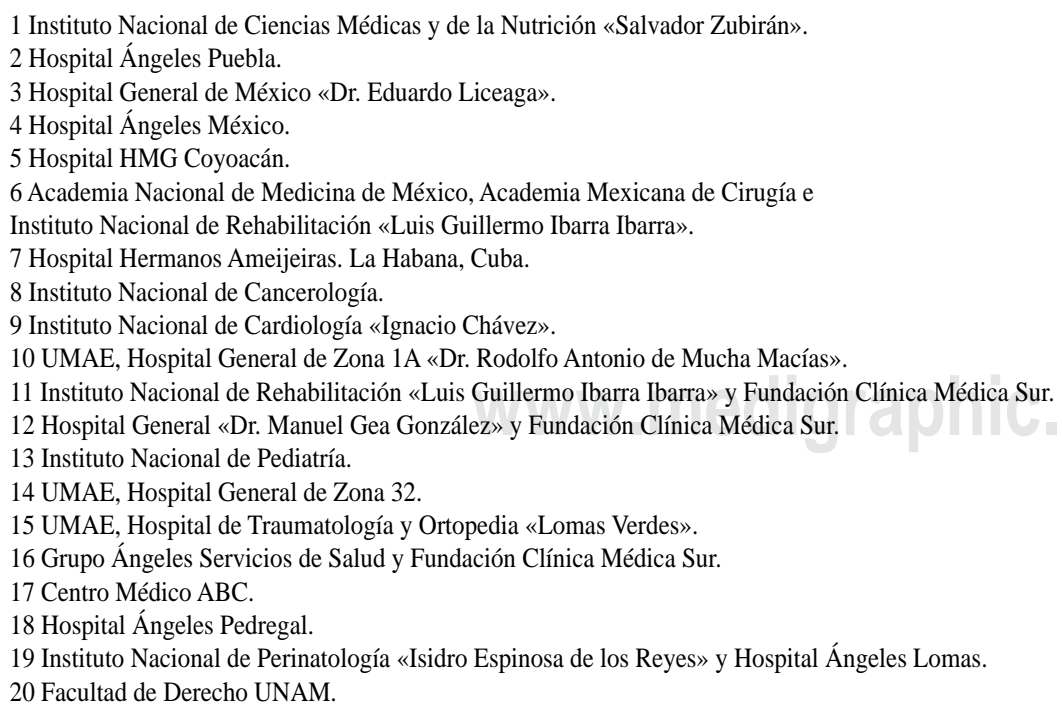




\section{SARS-COV-2/COVID-19 CONSIDERACIONES GENERALES}

Acad. Dr. Raúl Carrillo-Esper, Dr. Jorge Raúl Carrillo-Córdova

A lo largo del siglo XXI, el ser humano ha enfrentado tres epidemias por coronavirus. En 2002 en la provincia china de Guangdong se reportaron casos de una nueva enfermedad de vías aéreas de rápida progresión a insuficiencia respiratoria, la cual afectó a 8,098 personas a nivel mundial causando 774 muertes, éste fue el inicio del síndrome de insuficiencia respiratoria aguda por coronavirus (SARS-CoV). Años después, en 2012, en la península arábica se reportó la presencia de un síndrome respiratorio (síndrome respiratorio del Oriente Medio, MERS-CoV), el cual se propagó a 27 países infectando cerca de 2,500 personas y cobrando la vida de 858 seres humanos. En diciembre de 2019, en la capital de la provincia china de Hubei, Wuhan, comenzó un brote de neumonías atípicas, el cual fue contenido sin éxito. Este nuevo coronavirus (SARS-CoV2) es el agente causal de la pandemia de COVID-19. Hasta el 10 de mayo de 2020, este virus ha infectado a 3,917,366, y matado a 274,361 personas a nivel mundial. En México, hasta el 10 de mayo de 2020 , se tiene un total de 35,022 casos confirmados y 3,465 defunciones.

Los coronavirus son una amplia familia de virus (Coronaviridae) que causan distintas afecciones en el ser humano, principalmente a nivel pulmonar. Son estructuras esféricas, el envoltorio proteico se caracteriza por presentar glicoproteínas transmembrana con la función de poder infectar células del enfermo. La proteína más importante es la glicoproteína transmembrana en pico o espina spike protein, la cual es convencionalmente llamada proteína $\mathrm{S}$.

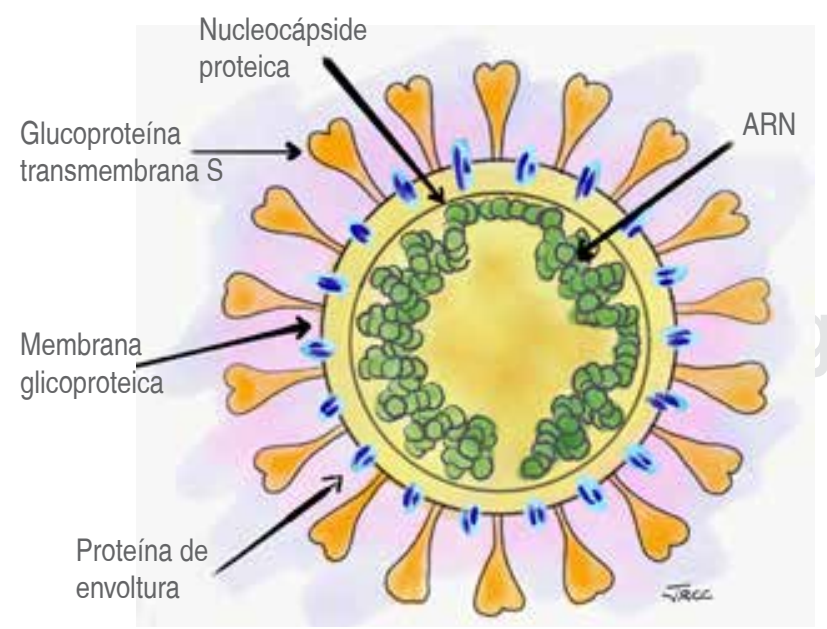

Dentro del envoltorio se encuentra el material genético viral, que es ARN. La entrada del coronavirus a las células hospederas es mediada por la glicoproteína transmembrana $\mathrm{S}$, la cual forma homotrímeros, mismos que protruyen de la superficie viral. La glicoproteína S se conforma por dos subunidades funcionales. La subunidad S1 regula la unión de la superficie del virus con la superficie celular, mientras que la subunidad S2 permite la fusión de ambas membranas con el objetivo de introducir el material genético del virus a la célula infectada para comenzar con la replicación viral. La unión de la glicoproteína S se realiza a los receptores de la enzima convertidora de angiotensina (ACE) tipo I y II.

\section{Interiorización viral mediante los receptores ECA-2}

El reservorio natural de este virus son los murciélagos y debido al contacto cercano y constante con seres humanos logró cruzar la barrera interespecie infectando personas, de manera similar a su antecesor el SARS-CoV1, agente causal del SARS.

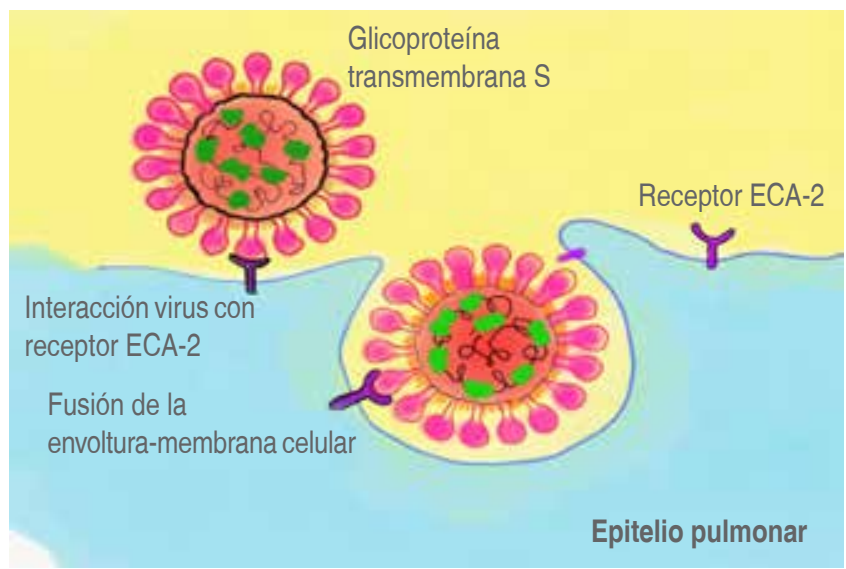

El SARS-CoV2 tiene una tasa de contagio de 2-3.5 con un período de incubación que va de los 5-20 días (media 6.5). La vía de transmisión es de persona a persona (a través de gotas y aerosoles) y por contacto de superficies contaminadas, hasta la fecha no existe información contundente que demuestre la transmisión fecal-oral. Dependiendo del material de la superficie la vida media del virus es variable, diversos estudios postulan hallazgos de partículas virales de 48 a 72 horas después de la contaminación. Las medidas preventivas tienen un papel fundamental en la mitigación de la propagación del virus. Se recomienda distancia de por lo menos un metro entre cada individuo, así como aseo de manos (con agua y jabón por 40 a 60 segundos o alcohol gel al $70 \%$ durante 30 segundos) de forma constante y des- 
pués de tener contacto con personas. La tasa de letalidad del virus alcanza hasta $10 \%$ de pacientes, dependiendo de la serie revisada; sin embargo, aún es una enfermedad con poco tiempo de estudio para establecer esta cifra con exactitud. Todas las personas son susceptibles de presentar infección por SARS-CoV2; sin embargo, existen factores para presentar un cuadro de mayor gravedad, destacando, edad mayor de 60 años, enfermedades crónico degenerativas con mal control (diabetes mellitus e hipertensión arterial sistémica), pacientes inmunocomprometidos, tabaquismo, entre otros.

La presentación del SARS-CoV2 se asemeja mucho a la de su antecesor (SARS-CoV1). La mayoría de los casos presentarán un cuadro de resfriado común, caracterizado por ataque al estado general, mialgias y tos. Conforme progresa la enfermedad, los síntomas respiratorios empeoran, caracterizándose por anosmia, disnea, dolor torácico, fiebre constante y desorientación. En los casos graves, la insuficiencia respiratoria aguda, el choque séptico y la falla orgánica múltiple desencadenan la muerte. De los estudios que se tienen hasta la fecha se ha demostrado que aproximadamente $80 \%$ de los pacientes presentarán una enfermedad leve, del resto $10 \%$ de pacientes podrán presentar enfermedad grave y hasta $5 \%$ serán pacientes en estado crítico que requerirán manejo en terapia intensiva. El SARS-CoV2 tiene la capacidad de afectar múltiples órganos y sistemas. Aunque la afección pulmonar es la más frecuente, existen otras manifestaciones a nivel cutáneo, ocular, hematológico, inmunológico, neurológico y genitourinario. La caracterización de la COVID-19 aún sigue actualizándose con el hallazgo de información nueva conforme transcurre la pandemia.

No existe vacuna ni tratamiento para el SARS-CoV2, por lo que se debe realizar una caracterización correcta de los síntomas con el fin de decidir el tratamiento a recibir. En casos leves están indicadas medidas de aislamiento social, así como soporte general. Se administran analgésicos, antipiréticos y abundantes líquidos. En casos que presenten deterioro o en pacientes que tengan sintomatología más florida (fiebre, disnea, etc.), se decide el internamiento con el fin de lograr adecuada hidratación y oxigenación pulmonar. En pacientes con cuadros graves de la enfermedad se requieren cuidados intensivos destacando ventilación mecánica invasiva, anticoagulación temprana de los pacientes, plasmaféresis y oxigenación por membrana extracorpórea. El diagnóstico de estos pacientes debe confirmarse mediante prueba de PCR.

Lesión pulmonar mediada por el coronavirus. A nivel pulmonar se puede manifestar como una lesión leve o grave, dependiendo de la cantidad de inflamación presente. En otros órganos se presenta como falla hepática aguda, lesión renal aguda o miocarditis viral

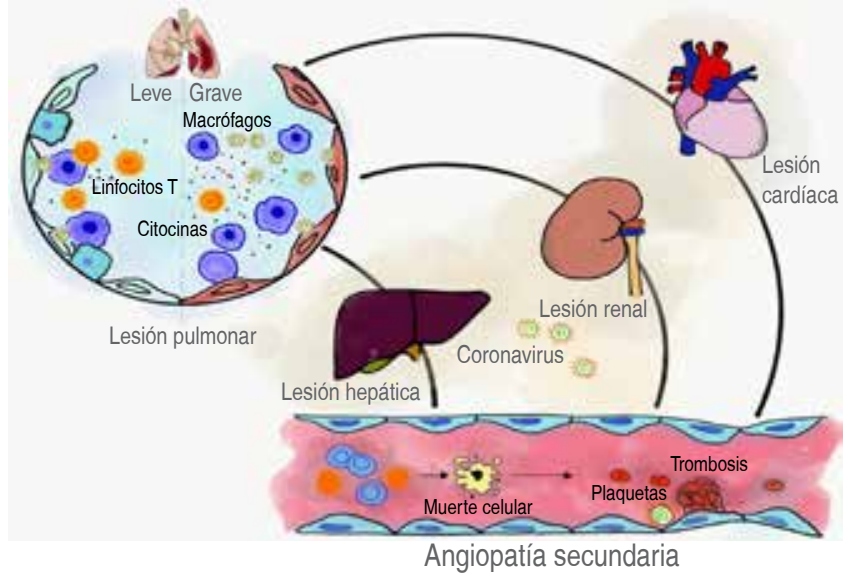

\section{EQUIPO DE PROTECCIÓN PERSONAL}

\section{Dra. Ana Lilia Garduño-López, Dr. Ricardo Eli Guido-Guerra, Dr. Víctor Manuel Acosta-Nava}

Durante la pandemia del COVID-19, el desarrollo de la experiencia en la colocación y el retiro del Equipo de Protección Personal (EPP) por más fácil que parezca, requiere de una comprensión tridimensional, es decir, conocimiento de la fisiopatología de la enfermedad (para saber qué equipo utilizar y en qué momento), la familiaridad con los pasos secuenciales para la colocación y el retiro del EPP (para disminuir los riesgos de contaminación y contagio) así como las habilidades psicomotoras con el EPP para realizar otros procedimientos (intubación, colocación de sonda nasoenteral, de catéter central o arterial entre otros). Esto requiere de capacitación y repetición de la estrategia, para adquirir confianza y seguridad emocional al usar el EPP.

\section{Aerolización}

Los coronavirus tienen aproximadamente 0.125 micras de tamaño y con frecuencia se transportan en gotitas respiratorias. El riesgo de aerolización en el aire y la transmisión del SARS-CoV-2 se ha observado durante la atención clínica de rutina y durante los procedimientos generadores de aerosoles. La formación de aerosoles se puede dividir en inducida por el paciente (por ejemplo, tos o estornudos) o inducidos mecánicamente (por ejemplo, intubación, succión abierta de secreciones, reanimación cardiopulmonar, broncoscopía, ventilación asistida, CPAP, BiPAP y ventilación oscilatoria de alta frecuencia). El anestesiólogo es el especialista con más experiencia en el manejo de la vía aérea, pero también uno de los trabajadores de salud que mayor riesgo tiene debido principalmente a los procedimientos que realizan los generadores de aerosoles. En hospitales reconvertidos 
a centros COVID, las cirugías electivas son diferidas y los anestesiólogos pueden salir del quirófano para incorporarse a equipos de manejo de vía aérea en zonas que les son poco familiares, con personal distinto con el que trabajan regularmente, lo que representa un riesgo aunado a las dificultades técnicas que implica usar el EPP. Por otro lado, tenemos hospitales que no atienden pacientes con COVID-19, pero anestesiólogos que trabajan en el día a día con la vía aérea, lo cual supone un riesgo en el entendido de que actualmente existen pacientes asintomáticos que pueden ser portadores del virus, por lo que deben utilizar de la misma forma EPP. Aunque se ha recomendado el uso del equipo completo EPP para los pacientes programados para cirugía que serán intubados y que son asintomáticos, es decir, no se sospecha infección, se debe considerar el abasto del material y ahorro de recursos ante esta pandemia, ya que en otros países ha sido un común denominador, razón por la cual se sugiere la selección de los componentes de este equipo dependiendo del procedimiento anestésico que se vaya a realizar basado principalmente en el riesgo de aerolización; sin embargo, en pacientes con COVID-19 y anestesia neuroaxial o regional, el EPP completo siempre debe estar disponible aunque no se utilice, en el entendido de la posibilidad de que el paciente requiera intubación o resucitación cardiopulmonar.

\section{Equipo de protección personal (EPP)}

Dentro de la protección para el personal, se debe considerar que el paciente con COVID-19 debe portar una mascarilla N95 durante el traslado hospitalario y manejo anestésico, siempre que esto sea posible. Si se administra sedación, se puede administrar oxígeno suplementario través de puntas nasales debajo de la mascarilla quirúrgica. Un dispositivo que no debe faltar cuando se da ventilación asistida o mecánica es el filtro HEPA o un filtro antiviral para reducir el riesgo de aerolización en el ambiente, este filtro se conecta lo más próximo al paciente, ya sea encima de la mascarilla facial o inmediatamente después de un tubo endotraqueal o mascarilla laríngea.

Para los procedimientos de generación de aerosoles, el EPP incluye protección para los ojos con goggles, se puede utilizar una escafandra o una careta, bata impermeable y de dos a tres pares de guantes para desechar un par de éstos durante la intubación, además de protección para las vías respiratorias con máscaras N95 o respirador aprobado por la NIOSH (Instituto Nacional de Seguridad y Salud Ocupacional). Es crucial el uso de un agente antiempañante en goggles (por ambos lados) y en la careta para evitar perder la visibilidad durante la atención del paciente. La higiene efectiva de las manos antes de ponerse y después de quitarse el EPP, incluidos los guantes, es muy importante. Los procedimientos para ponerse y quitarse la ropa, desechar el

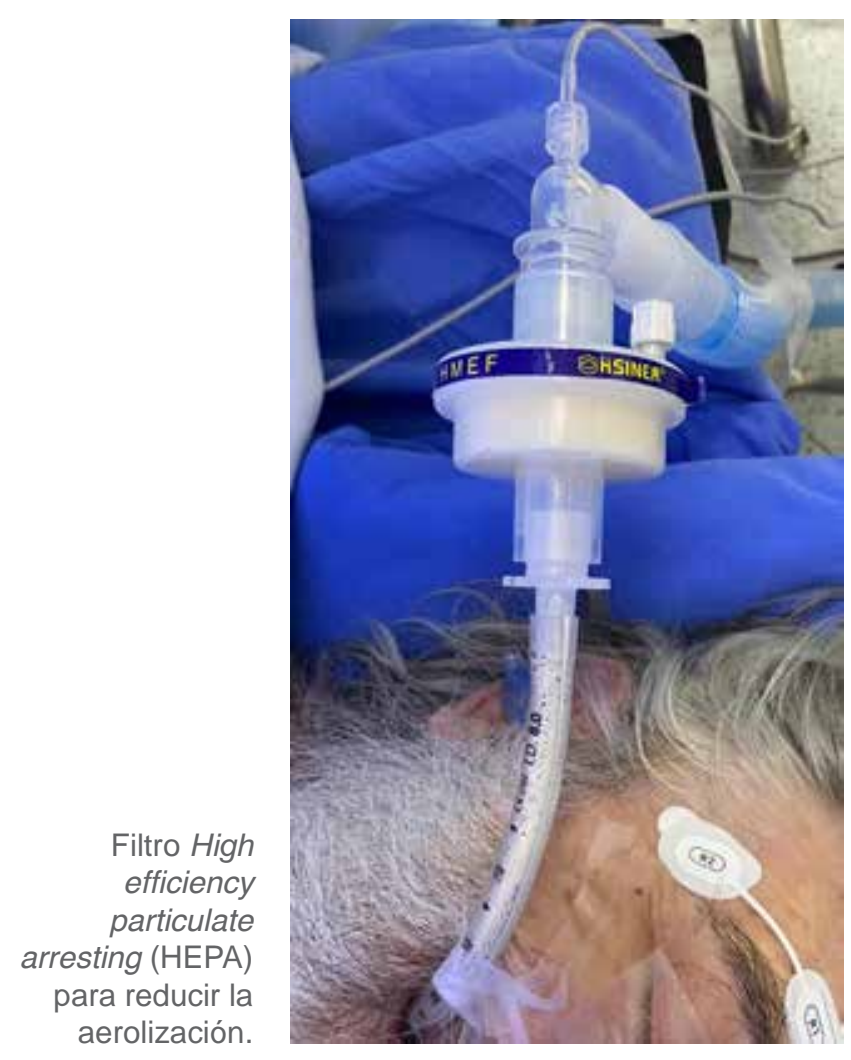

EPP contaminado y limpiar el EPP reutilizable contaminado y el equipo de anestesia deben establecerse siguiendo las recomendaciones institucionales. Los respiradores aprobados (NIOSH) que se usan típicamente en las industrias de construcción y fabricación, pero que en la actualidad no cumplen con los requisitos de la Administración de Alimentos y Medicamentos (FDA) pueden ser efectivas para proteger al personal de atención médica de la exposición en el aire, incluido COVID-19. En el caso del overol éste no ha sido recomendado por la CDC, la razón principal puede ser porque propicia la contaminación del trabajador de la salud al ser retirado; sin embargo, no está contraindicado, éste podría utilizarse para protección total $\left(360^{\circ}\right)$ contra sangre y fluidos ante mayor tiempo de exposición, siempre y cuando esté disponible, el personal esté capacitado para el retiro y se toleren los inconvenientes como el calor durante su uso en períodos más prolongados.

\section{Caja de aerosoles (Aerosol Box, AeroBox)}

La caja de aerosoles es un dispositivo quizá bueno para proteger contra salpicaduras directas producidas por la tos del paciente hacia la cara del especialista en procedimientos, puede funcionar para intubaciones electivas sin complicaciones; sin embargo, si el paciente está bien relajado para la 
Equipo de Protección Personal de acuerdo con su uso durante el perioperatorio.

\begin{tabular}{|c|c|c|c|c|c|c|c|}
\hline Escenario clínico & $\begin{array}{l}\text { Retiro } \\
\text { de cosas } \\
\text { personales } \\
\text { e higiene de } \\
\text { manos }\end{array}$ & $\begin{array}{c}\text { Gorro } \\
\text { quirúrgico }\end{array}$ & $\begin{array}{c}\text { Botas } \\
\text { quirúrgicas } \\
\text { impermeables }\end{array}$ & $\begin{array}{l}\text { Protección } \\
\text { ocular }\end{array}$ & $\begin{array}{l}\text { Cubrebocas/ } \\
\text { bata } \\
\text { quirúrgica }\end{array}$ & Guantes & $\begin{array}{l}\text { Protección facial en } \\
\text { caso de intubación } \\
\text { OT (se puede utilizar } \\
\text { cualquiera de éstos) }\end{array}$ \\
\hline $\begin{array}{l}\text { Evaluación de la vía aérea y } \\
\text { exploración física* }\end{array}$ & & & & & & & \\
\hline $\begin{array}{l}\text { Paciente quirúrgico sin } \\
\text { sospecha de estar infectado } \\
\text { AGB o intubación o extubaci }\end{array}$ & & & & & & & \\
\hline $\begin{array}{l}\text { Paciente sospechoso o } \\
\text { infectado por COVID-19 que } \\
\text { requiere anestesia regional o }_{\text {neuroaxial }^{* *}}\end{array}$ & & & & & & & \\
\hline $\begin{array}{l}\text { Paciente sospechoso o } \\
\text { infectado por COVID-19 } \\
\text { que requiere intubación o } \\
\text { extubación OT o AGB }{ }^{\star \star *}\end{array}$ & & & & & & & \\
\hline
\end{tabular}

* El cubrebocas tricapa es resistente a fluidos y aerosoles, pero no hace un buen sello, se recomienda durante cortos períodos por su vida media.

** En anestesia central o periférica en pacientes con COVID-19 siempre se debe tener disponible el EPP completo, por el riesgo de intubación o paro cardiaco por intoxicación de anestésicos locales, por lo cual es necesario tener disponibles bata, goggles y careta.

*** El overol puede utilizarse cuando está disponible, pero se debe tener mucha precaución al retirar, por el riesgo de contaminación. Se requiere protección facial durante procedimientos que provocan aerolización, ya sea con careta o escafandra o respirador facial completo (avalado por NIOSH), en este caso no se utilizará mascarilla N95.

$\mathrm{AGB}=$ anestesia general balanceada, $\mathrm{OT}=$ orotraqueal.

intubación con un plan de equipo claro y una coordinación bien entrenada, la utilidad de la caja puede ser de valor limitado. A pesar del nombre de «Aerosol Box», hay dudas si protege o no contra los aerosoles y puede ser un poco inapropiado. Un aerosol es una suspensión de partículas pequeñas (0.001 a $100 \mathrm{uM}$ ), que puede transportar virus vivos por hasta tres horas, se genera potencialmente durante el proceso de intubación traqueal y tiene potencial para largo alcance transmisión al personal de asistencia. La caja no es útil ni practica en los pacientes con vía aérea difícil, los obesos y en pacientes con cuello corto. Sin embargo, en caso de no contar con careta o cubrebocas N95 o para pacientes quirúrgicos que serán intubados y son asintomáticos, esta podría ser una buena opción de protección.
La magnitud de la pandemia ha afectado el abasto de equipo de protección personal en muchos sitios; la asignación de estos recursos debe ser juiciosa para maximizar su uso y evitar el desperdicio. Se debe prever la situación de escasez y planear qué medidas alternativas se podrían efectuar para proveer al personal de equipos de protección en ese caso, por ejemplo: uso extendido de cubrebocas personales N95 (hasta 40 horas), así como protocolos de descontaminación de éstos con peróxido de hidrógeno o luz ultravioleta para su reúso. La protección de los trabajadores de salud es prioritaria; si el personal de salud se enferma, merma la fuerza laboral para combatir la pandemia, se convierte en un paciente más que cuidar y pone en riesgo al resto del equipo de atención. 


\section{MANEJO DE LA VÍA AÉREA EN EL PACIENTE CON COVID-19}

\section{Dr. Miguel Ángel García-Lara, Dra. Nora Lorena López-León}

El manejo de la vía aérea (VA) durante la crisis generada por la pandemia de COVID-19 impsslica un alto grado de riesgo para el paciente, así como para el personal de salud. Esto debido a la aerolización del virus. Sin embargo, es preferible realizar una intubación programada a encontrarse en la necesidad de cambiar la técnica anestésica durante la cirugía. Los pacientes COVID-19 pueden generar «hipoxemia silenciosa». Lo principal es no generar aerosol y evitar un contagio en el personal de salud, por lo tanto, se puede hacer uso de los siguientes pasos:

1. Asegúrese de contar con el equipo de protección personal adecuado (mascarilla N95, goggles, bata, doble gorro, doble guante, etc.) corroborando que no exista exposición de su piel. Contar con dispositivos de vía área convenientes para el procedimiento (tubo con globo de varios calibres, laringoscopio con varias hojas o videolaringoscopio, guía metálica, jeringa, filtros para el circuito anestésico, etc.). El uso del equipo de protección es incómodo y los goggles o caretas se pueden empañar, los antiempañantes pueden ser una buena opción. La caja transparente de intubación puede incrementar la seguridad del procedimiento.

2. Realice una lista de chequeo previo al procedimiento para identificar faltantes o posibles fallos.

3. El procedimiento se debe realizar por dos personas con experiencia en el manejo de vía aérea y sólo debe estar el personal indispensable dentro de quirófano.

4. Si se identifica una potencial vía aérea difícil (VAD), verbalice el posible plan de intubación.

5. Busque mejorar la posición del paciente como colocarlo en rampa o Trendelenburg invertida.

6. Una persona maneja la VA y la segunda asiste en el paso de medicamentos, ventilación, programación de máquina de anestesia, asistencia en maniobras como BURP, etc. Proteja monitor y máquina de anestesia, éste puede ser un fómite posteriormente.

7. Al ingreso del paciente a quirófano, coloque mascarilla facial con el mejor sello posible. Preoxigenación con $\mathrm{FiO}_{2}$ al $100 \%$ por tres minutos, con válvula APL abierta. Optimice las condiciones de intubación: uso de terapia de líquidos, vasopresores e inotrópicos.

8. La ventilación con bolsa mascarilla es un procedimiento con alto riesgo de generar aerosol y dispersión del virus, por lo que en la medida de lo posible deberá evitarla. La técnica de intubación en secuencia rápida es la mejor opción, siempre que las condiciones del paciente lo per- mitan. Recuerde que aun con buena preoxigenación, estos pacientes no toleran la apnea por mucho tiempo.

9. Seleccione el fármaco inductor y opioide según la clínica. El relajante neuromuscular (RNM) puede ser rocuronio a $1.2 \mathrm{mg} / \mathrm{kg}$ o succinilcolina a dosis de $1 \mathrm{a} 1.5 \mathrm{mg} / \mathrm{kg}$.

10. Después de la pérdida del estado de conciencia y que la posibilidad de tos sea baja, puede usar cánula de Guedel y aplicar poca presión (CPAP) para minimizar necesidad de ventilación. Asegure adecuado sellado con la mascarilla facial.

11. Es posible realizar una intubación con laringoscopía convencional, pero es más conveniente usar videolaringoscopio con pantalla separada, muy recomendado. Colocar guía metálica o Bougie al tubo endotraqueal disminuye el número de intentos.

12. Durante la colocación del tubo endotraqueal, asegúrese de que el globo pasó las cuerdas vocales antes de inflarlo. La presión del globo debe ser entre 20 y 30 cmH2O.

13. Puede ocluir la luz del tubo con una pinza o con un tapón mientras realiza la colocación del circuito de ventilación. Despince el tubo una vez asegurado el sellado de la VA.

14. Una vez conectado, confirme la adecuada colocación del tubo (auscultación, curva de capnografía, uso de ultrasonido o movimientos torácicos), y fije el tubo adecuadamente.

15. La ventilación mecánica y el manejo de los parámetros o modos ventilatorios deben ser controlados por el personal que asiste.

16. Ante una VAD no predicha, el uso de dispositivos supraglóticos puede mejorar la ventilación, pero no disminuye el riesgo de generar aerosol. Recuerde que existen algoritmos para VAD, pero algunas recomendaciones incrementan la posibilidad del riesgo de generar aerosoles (intubación retrógrada, fibroscopio, intubación despierto, intubación con fibroscopio asistida por videolaringoscopio y VA quirúrgica).

17. Seleccione técnica anestésica (general balanceada vs. TIVA) según criterio clínico y programe ventilador con parámetros de protección pulmonar. Administre antiemético con tiempo suficiente a la extubación.

18. Para la extubación, aspire secreciones y elija cánula rígida sobre la flexible y evalúe si las condiciones clínicas para la emersión son óptimas. De no ser así, considere mantener intubado al paciente y pasarlo a una Unidad de Terapia Intensiva.

19. Sólo en caso de ser necesario realice la reversión del relajante neuromuscular (en caso de rocuronio, sugammadex entre 2 y $4 \mathrm{mg} / \mathrm{kg}$ es buena dosis inicial). Otros fármacos para reversión de RNM pueden aumentar el riesgo de generar secreción y aerosoles.

20. Al retirar el tubo endotraqueal, cierre los flujos de aire fresco, sólo durante el proceso de movilización del tubo, con la finalidad de generar menor cantidad de aerosol. 
Después de la extubación, coloque mascarilla facial sobre el paciente con adecuado sellado y reinicie el flujo de gases frescos. Intercambiador de tubo de VA está relativamente contraindicado en pacientes COVID-19 por riesgo de generar tos.

21. Recuerde en todo momento contar con un área asignada o contendor para colocar el equipo de VA contaminado.

22. Los pacientes COVID-19 requieren estar aislados durante su estancia en recuperación postanestésica o considere hacer la recuperación dentro del mismo quirófano.

\section{Conclusiones}

Priorice su seguridad ante todo. Como lo sugieren los algoritmos de VAD, pida ayuda si es necesario y mantenga la calma, el estrés dificulta más la toma de decisiones, la respiración y la visión con el equipo de protección usado para manejo del paciente con diagnóstico de COVID-19.

\section{POR QUÉ POSPONER LAS CIRUGÍAS ELECTIVAS Y NO LAS URGENTES O EMERGENTES DURANTE LA PANDEMIA DE COVID-19}

\section{Dr. Gabriel E Mejía-Terrazas}

Actualmente existe una reorganización de los servicios quirúrgicos y anestésicos en todo el mundo, ya que además de existir pacientes que requieren manejo quirúrgico (en algunas ocasiones urgente o a corto plazo) con cuidado intensivo postoperatorio (cirugías mayores, incluyendo las cardíacas y oncológicas), también existe un gran número de pacientes con sospecha o confirmación de COVID-19 que ameritan atención hospitalaria e incluso ingreso a UCI. Aun cuando cada colegio y sociedad han emitido sus propias recomendaciones al respecto, todos han coincidido en el aplazamiento no mayor de ocho semanas (de ser posible y tomando en cuenta las características del paciente y su enfermedad) de todas las cirugías electivas y esenciales, dadas las consideraciones etiopatológicas relacionadas con el trauma quirúrgico, la infección por SARS-CoV-2 y la presencia de comorbilidad.

Existe evidencia de la redistribución de linfocitos del área vascular al tejido linfático con subsecuente linfopenia y de la respuesta inmunológica producida por el trauma quirúrgico al estimular la secreción de diversos mediadores inflamatorios que incluyen citocinas, especies reactivas de oxígeno, óxido nítrico, factor activador de plaquetas, factores de crecimiento y eicosanoides, mismas que a su vez activan los leucocitos polimorfonucleares, células endoteliales, macrófagos y linfocitos, y que pudieran agravar una infección por SARS-CoV-2 o aumentar la susceptibilidad de los pacientes a infectarse. En condiciones normales algunas citocinas funcionan como reguladoras de la inmunidad para limitar el daño o la respuesta inflamatoria excesiva, por lo que debe existir un equilibrio dinámico entre las citocinas proinflamatorias y antiinflamatorias para evitar la disfunción orgánica e infección y por lo tanto, reducir la morbilidad y mortalidad postoperatoria. Dicho equilibrio podría alterarse en pacientes con compromiso inmune asociado a la infección por SARS-CoV-2 caracterizado por incremento en la secreción de citocinas proinflamatorias descrito con anterioridad, en particular de IL-6, cuyos niveles se han observado significativamente elevados (un marcador asociado con severidad de pacientes críticos, aparición de falla orgánica y disfunción miocárdica durante la sepsis en los pacientes con neumonía severa.

Los pacientes programados para cirugía durante el período de incubación de COVID-19, aunque en apariencia están sanos, no están libres de la infección por SARS-CoV-2 y por lo tanto, ya inició la replicación viral y los cambios inmunológicos asociados. Lei y colaboradores reportaron que en 34 pacientes sometidos a cirugía electiva durante el período de incubación de COVID-19, todos desarrollaron neumonía a corto plazo después de la cirugía, $44.1 \%$ requirieron ingreso a UCI y 20.5\% murieron después de la admisión a UCI, siendo las principales complicaciones ARDS, choque, arritmia y falla cardíaca aguda, por lo que la cirugía puede acelerar o exacerbar la progresión de COVID-19. Si bien los pacientes en período de incubación de COVID-19 que ingresaron a UCI después de la cirugía fueron de mayor edad, estuvieron sometidos a cirugías más complicadas y presentaron mayor frecuencia de comorbilidad, se recomienda que todo paciente programado para cirugía tenga un período de aislamiento de 14 días o bien se excluya la infección en el paciente antes de ser considerado para cirugía electiva durante la pandemia de COVID-19.

En el caso de pacientes con cirugía cardíaca se ha reportado alteración en la expresión de la proteína de superficie de monocitos HLA-DR (implicada en la respuesta a patógenos) e inhibición de las funciones monocíticas y dendríticas, factores asociados con estancia más prolongada en UCI y mayor mortalidad en casos de infección severa, que al agregarse al riesgo de infección por SARS-CoV-2 podrían ser catastróficos para los pacientes.

En cuanto a los pacientes oncológicos, se ha sugerido un incremento en el riesgo a desarrollar infección severa por SARS-CoV-2, probablemente por la inmunodepresión asociada. Liang y colaboradores reportaron que $75 \%$ de los pacientes con neoplasia que fueron operados o tratados un mes previo a la infección por SARS-CoV-2 presentaron enfermedad severa.

Por otro lado, algunos marcadores asociados a mal pronóstico en pacientes oncológicos también lo son en 
pacientes con COVID-19, lo que genera mayor preocupación, por ejemplo, en pacientes con cáncer colorrectal una relación $\mathrm{N} / \mathrm{L}>2.8$ incrementa el riesgo de complicaciones postoperatorias a dos años (Hazard-Ratio [HR] de 5.36, IC 95\%: 1.95-14.90), mientras que en pacientes con COVID-19 una NLR elevada es un factor de riesgo independiente de mortalidad hospitalaria.

En cuanto a los procedimientos quirúrgicos urgentes y emergentes (incluyendo procedimientos quirúrgicos superficiales y periféricos), así como ciertos procedimientos diagnósticos, éstos pueden realizarse en áreas de cirugía ambulatoria disponibles o acondicionadas en áreas alejadas de los servicios de urgencias y terapia intensiva. Se incluyen los relacionados con trauma (fracturas, luxaciones, reparaciones tendinosas, síndrome compartimental y drenajes de abscesos o hematomas), los relacionados con cáncer (diagnósticos o terapéuticos), los procedimientos urológicos con el potencial de progresión a obstrucción/infección o dolor severo que amerite hospitalización, o incluso ciertos procedimientos intraabdominales emergentes (por ejemplo, apendicectomía y colecistectomía). Dichos procedimientos deben realizarse en pacientes sin sospecha clínica de COVID-19 y de ser posible negativo a infección por SARS-CoV-2 confirmada por PCR. Si el paciente es sospechoso o diagnosticado con COVID-19 o el procedimiento a realizar pone en peligro la vida del paciente, debe ser manejado dentro del quirófano del hospital siguiendo los protocolos específicos de cada paciente y condición.

\section{RECOMENDACIONES PARA CIRUJANOS ANTE LA PANDEMIA DE COVID-19}

\section{Dra. Leslian Janet Mejía-Gómez}

A continuación, se presenta una serie de recomendaciones que orientan a la toma de decisiones para el cirujano que se deben tomar en cuenta durante un procedimiento quirúrgico para evitar el riesgo de transmisión y contagio para el equipo de salud y deben ser adaptadas a las normas institucionales. Estas recomendaciones están basadas en las recomendaciones emitidas por la Asociación Española de Cirujanos, el American College of Surgeons y la Sociedad Mexicana de Cirugía General (SMCG).

\section{Consideraciones especiales ante la pandemia}

En general se pueden posponer las cirugías electivas durante una pandemia y emergencia nacional como la que se han decretado en nuestro país.

Considerar disminuir las concentraciones de personas en las salas de espera, ya que son altos focos de contagio y diseminación en las áreas hospitalarias.
Cancelar la consulta externa que no sea prioritaria.

Se debe evitar programar cirugía ambulatoria, primordialmente a pacientes mayores de 60 años, postergar las cirugías electivas o complejas no urgentes.

\section{Cirugía en pacientes COVID-19}

Existe la posibilidad de que durante la cirugía tanto abierta, laparoscópica o robótica haya exposición y alta contaminación viral del equipo quirúrgico, por lo cual se deben considerar sólo cirugías de urgencias, y emplear estrictamente medidas de protección para la seguridad del personal. Se debe disponer de un quirófano específico sólo para pacientes COVID-19, y contar con las medidas de protección específicas.

Las indicaciones de cirugía deben ser contempladas con el máximo rigor de los principios de prevención y control de infecciones. Al considerar el método quirúrgico debe hacerse con precaución. Todos los pacientes sometidos a cirugía de urgencia deberán ser considerados como caso sospechoso.

Los pacientes se deben clasificar en tres escenarios potenciales:

a) Caso positivo confirmado: prueba PCR positiva.

b) Caso sospechoso con síntomas: sin prueba confirmatoria.

c) Caso sospechoso, asintomático (probable período de ventana).

Previo al procedimiento quirúrgico se debe realizar el interrogatorio directo o indirecto de rutina, viajes al extranjero, visita a sitios concurridos, contacto con personas positivas a COVID-19 o con sospecha, si hay presencia de signos y síntomas relacionados: fiebre (mayor de $37.8{ }^{\circ} \mathrm{C}$ ), cefalea, tos seca, anosmia, disgeusia, odinofagia, mialgias, artralgias, diarrea, etc. La ausencia de síntomas no excluye al paciente de probable infección.

La higiene de manos debe realizarse meticulosamente en especial después de quitarse los guantes, después del contacto con áreas sucias o contaminadas, y después de cada contacto con el paciente (por ejemplo: colocación de termómetro, sonda nasogástrica).

La protección del equipo médico es fundamental, se requiere atención cuidadosa para evitar la autocontaminación.

Equipo necesario:

- Se recomienda también afeitarse la barba para favorecer la adecuada fijación y funcionamiento de las mascarillas.

- Se debe evitar portar anillos, relojes, pulseras, aretes.

- Bata impermeable. 
- La mascarilla quirúrgica convencional no ofrece protección contra los aerosoles, es necesario usar mascarillas tipo N-95, o FFP2/FFP3 (filtran 96 y 99\% respectivamente).

- Gafas: es fundamental la cobertura ocular de pantalla completa.

- Pantalla de cobertura facial: no protege de los aerosoles, pero es necesaria cuando existe riesgo de salpicaduras (sangre, vómito y otros líquidos biológicos).

- Guantes de nitrilo largos.

- Uso de overol impermeable cuando está disponible.

- Una vez puesto el equipo de protección personal (EPP) antes de comenzar el procedimiento quirúrgico se colocará sobre el equipo estéril un lavado quirúrgico con alcohol en gel sobre los guantes de base y se colocará posteriormente la bata y guantes estériles habituales.

Sala de quirófano: deberá permanecer dentro la menor cantidad de personal, el mínimo indispensable. Todos deberían usar EPP y protección visual. La intubación y extubación deberá hacerse en el quirófano dentro de una sala de presión negativa.

Debe evitarse el uso de electrocirugía monopolar, disectores ultrasónicos, bisturí ultrasónico y dispositivos bipolares avanzados o utilizar en la configuración más baja posible, ya que pueden producir aerolización y dispersión de partículas mediante los vapores. Se recomienda el uso de lápices de diatermia monopolar conectados con evacuadores de humo, o tener el aspirador siempre en cercanía del área de electrocoagulación.

Cirugía laparoscópica: se debe evitar y valorar el riesgobeneficio, durante los procedimientos laparoscópicos hay mayor dispersión de aerosoles, las recomendaciones para enfermedades altamente transmisibles asociadas a virus están basadas en estudios previos, no hay aún suficiente evidencia de que los filtros y medidas improvisadas, como circuitos cerrados de aspiración, sean confiables.

Considerar siempre que existe alto riesgo de contagio por aerolización durante los procedimientos laparoscópicos, por lo que la recomendación es realizar este tipo de cirugías con mascarillas faciales con alto porcentaje de filtración de partículas (N95) y filtros en sala quirúrgica para evacuar el neumoperitoneo y $\mathrm{CO}_{2}$ liberado. Contra partículas en aerosol en caso de contar con este tipo de equipo de protección la recomendación es que se realicen procedimientos laparoscópicos utilizando además una presión baja (recomendable 8-10 mmHg). La vía de abordaje quirúrgico deberá ser la de mayor beneficio para el paciente, las incisiones para los puertos deben ser lo más pequeñas posible para permitir el paso de los puertos, y evitar fugas alrededor de ellos. La presión de insuflación de $\mathrm{CO}_{2}$ debe mantenerse al mínimo y debe utilizarse ultrafiltración (sistema de evacuación de humo o filtración) si está disponible. Es importante consi- derar que todo neumoperitoneo debe evacuarse de manera segura a través de un sistema de filtración antes del cierre, extracción del trocar, extracción de la muestra o conversión para abrir. Se recomienda no usar drenajes, ya que existe mayor diseminación viral.

La indicación de cirugía urgente se individualizará en todos los casos y tratará de realizarse basándose en un diagnóstico con la mayor certeza posible.

\section{ANESTESIA REGIONAL EN LOS PACIENTES CON SARS-COV-2/COVID-19}

\section{Dr. Gabriel E Mejía-Terrazas}

Se debe tener presente que los procedimientos de anestesia regional tanto centrales como periféricos debe realizarlos el médico anestesiólogo con mayor experiencia, con el fin de evitar lo más posible la conversión de una técnica regional a anestesia general, ya que una intubación urgente en el contexto de la pandemia por COVID-19 puede ser más compleja que en el ámbito normal.

La planeación es un aspecto muy importante, por lo que deben tomarse en cuenta los tiempos de duración de la anestesia y cirugía; es mejor realizar una intubación planeada al inicio del procedimiento con todas las medidas de protección y sin prisas ni más dificultades que una intubación de emergencia.

No se recomienda reducir las dosis de anestésicos locales ni dejar fluir el líquido cefalorraquídeo por el riesgo de contaminación del personal.

Tener presente que debe evitarse realizar procedimientos adicionales como bloqueos periféricos y colocación de catéteres epidurales, ya que se requiere mayor contacto con los pacientes al vigilar esta modalidad analgésica, $\mathrm{y}$ esto aumentan el riesgo de contaminación cruzada, por lo que es recomendable utilizar analgesia postoperatoria intravenosa.

\section{Anestesia espinal y epidural}

Durante la pandemia de COVID-19 se han reportado diversas series de casos, principalmente cesáreas de urgencia, manejados con bloqueo subaracnoideo y/o bloqueo epidural, aunque no son los únicos procedimientos que se han realizado bajo anestesia espinal. Chen y colaboradores reportaron 17 pacientes con COVID-19 que presentaban datos de neumonía en la tomografía de tórax, sin trombocitopenia, pero con hipotensión importante en $86 \%$ de los casos, que fueron sometidas a cesárea con bloqueo epidural con técnica estándar, donde no se observaron complicaciones ni sintomatología secundaria en el postoperatorio y la mayoría fueron dadas de alta entre los seis y 13 días postoperatorios. Respecto al personal de salud, no reportaron ningún caso de contagio 
de SARS-CoV-2 entre los 10 anestesiólogos que intervinieron en las 17 cesáreas. Xia $\mathrm{H}$ y colaboradores reportaron un caso de bloqueo subaracnoideo con técnica estándar para una cesárea de emergencia, en el cual la paciente con infección por SARS-CoV-2 presentaba datos de neumonía en la tomografía de tórax, saturación de $\mathrm{O} 2$ de 92-93\% y pruebas de coagulación normales. La cirugía se realizó sin contratiempos, salvo por la presencia de tos, hipotensión transitoria y taquicardia ( $>138$ latidos por minuto) durante la cirugía. La analgesia postoperatoria se efectúo a través del catéter epidural insertado y ninguno de los médicos que intervinieron en el procedimiento resultó infectado. Zhong Q y colaboradores reportaron el uso de bloqueo subaracnoideo en 49 pacientes con datos clínicos y radiológicos de COVID-19 y confirmación infección por SARS-CoV-2 mediante RT-PCR en $26.5 \%$ de los casos en quienes se realizó cesárea o cirugía ortopédica de urgencia. Todos los pacientes presentaban síntomas respiratorios leves, 53.1\% fiebre y ninguno presentó trombocitopenia. Previo a la anestesia espinal se administraron antieméticos profilácticos; sin embargo, 6.1\% de los casos presentó vómito. Todos los pacientes tuvieron una adecuada evolución clínica y postoperatoria, ya que ninguno de los pacientes desarrolló neumonía severa o falleció por COVID-19. Respecto al personal de salud, posterior a la administración de los bloqueos subaracnoideos en los que participaron 44 anestesiólogos, cinco de ellos presentaron infección por SARS-CoV-2. Al analizar el tipo de PPE que utilizaron, se observó que cuatro de los siete anestesiólogos que utilizaron PPE categoría 1 (57.1\%) y sólo uno de los 37 anestesiólogos que utilizaron PPE categoría 3 (2.7\%) se infectaron, por lo que el uso de PPE categoría 3 muestra una reducción del riesgo relativo de 95.3\% (IC 96\%: 63.7-99.4, $\mathrm{p}<0.01$ ). En general, la mayoría de los autores coinciden en que las técnicas regionales producen menor riesgo tanto para los pacientes como para el personal sanitario, siempre y cuando se tomen en consideración las condiciones clínicas de cada paciente y las medidas de protección personal.

\section{Bloqueo de nervios periféricos}

Si se realiza bloqueo de nervios periféricos guiado por ultrasonido, debe protegerse todo el equipo (transductor, pantalla y teclado), en el caso del transductor pueden utilizarse fundas plásticas de cámaras, para el equipo se pueden utilizar las bolsas transparentes para cobertura de los fluoroscopios, ya que además de protegerlo, permite la manipulación adecuada de los controles y la visualización de la imagen. La sedación debe administrarse juiciosamente (ya que los pacientes con infección por SARS-CoV-2 presentan una función pulmonar limitada) y se recomienda el uso de mascarillas faciales completas teniendo la precaución de utilizar el menor flujo de $\mathrm{O} 2$ posible para mantener una saturación adecuada, ya que las distancias de dispersión del aire exhalado aumentan con el incremento del flujo de $\mathrm{O} 2$ (distancias laterales de $0.2,0.22$, 0.3 y $0.4 \mathrm{~m}$ desde el plano sagital durante el suministro de oxígeno a 4, 6, 8 y 10 L min- respectivamente), siempre monitoreando el CO2 expirado. No se recomienda el uso de puntas nasales debido a la posible aerolización con el flujo de O2. Se deben evitar los bloqueos periféricos que puedan reducir la capacidad pulmonar o los que pueden producir neumotórax, entre los que se incluyen: bloqueo interescalénico, bloqueo supraclavicular y bloqueo infraclavicular. Asimismo, se debe tener en mente que pueden presentarse las complicaciones habituales de estos procedimientos y que puede requerirse la manipulación de la vía aérea, para lo cual se debe contar con el material y equipo necesario.

\section{ANESTESIA EN PACIENTES EMBARAZADAS CON SARS-COV-2/COVID-19}

\section{Dra. Ma. del Rocío A Alcántara-Muñoz \\ Manejo clínico de la paciente hospitalizada con diagnóstico de SARS-CoV-2}

Durante su estancia en hospital la paciente debe mantenerse en aislamiento. No se contempla acompañamiento por familiar. La paciente deber ser monitorizada mediante signos vitales (presión arterial, frecuencia cardíaca, frecuencia respiratoria, oximetría de pulso, temperatura) cuatro veces al día y vigilancia de la frecuencia cardíaca fetal 1 vez por día. En aquellas pacientes que ingresaron por diagnóstico de SARS-CoV-2 + alguna causa obstétrica, se debe atender la causa obstétrica de acuerdo a los protocolos hospitalarios para cada complicación (preeclampsia, amenaza de parto pretérmino, ruptura prematura de membranas, etcétera).

\section{¿Cuándo debo considerar interrumpir el embarazo en una paciente con SARS-CoV-2?}

En pacientes estables no hay indicación de interrumpir el embarazo. Siempre que se pueda, se mantendrá la gestación a término. La decisión de interrumpir el embarazo en pacientes no estables se hará bajo consenso multidisciplinario por evolución desfavorable de acuerdo al deterioro materno.

Se debe vigilar el bienestar materno y fetal. En el caso de la vigilancia fetal, la realización de monitoreo electrónico continuo de la frecuencia cardíaca fetal durante 20 minutos puede ayudarnos a identificar cambios en la fisiología fetal reflejado en patrones normales y anormales de la misma.

En el caso del monitoreo materno se hará bajo criterios de gravedad por falla orgánica en consenso multidisciplinario. 
No existe aún evidencia de que el parto vaginal o por cesárea sea mejor uno que el otro en el contexto de infección por SARS-CoV-2. La indicación de cesárea se hará de acuerdo al deterioro materno o fetal para acortar el primer período de trabajo de parto.

\section{¿Qué tipo de anestesia elegir?}

Las pautas de la APSF (Anesthesia Patient Safety Foundation) para el manejo de embarazadas que son positivas a Covid-19 o que son personas con sospecha, se recomienda siempre para el personal:

1. Aislamiento.

2. Visita preanestésica por teléfono o videollamada.

3. Mascarilla quirúrgica para la paciente todo el tiempo.

4. El personal de salud debe usar protección personal todo el tiempo (bata, guantes, mascarilla N95 y careta).

5. Ponerse y quitarse el equipo de protección lleva tiempo, anticipe emergencias.

- La analgesia epidural temprana puede reducir la necesidad de anestesia general para un parto por cesárea emergente.

- Un diagnóstico positivo de COVID-19 no se considera una contraindicación para la anestesia neuroaxial, a menos que no cuente con tiempos de coagulación o INR necesarios marcados por las guías internacionales.

- Evite la cesárea por urgencia tanto como sea posible: comunicación proactiva con equipos de obstetricia y enfermería. Para la dificultad respiratoria intubar temprano usando EPP apropiado (equipo de protección personal).

- Asigne el anestesiólogo más experimentado siempre que sea posible para los procedimientos (neuroaxial, intubación).

- Considere minimizar el uso de residentes en el cuidado directo de pacientes con COVID-19. Minimice la cantidad de personal en la sala.

6. Antes de ingresar al quirófano, independientemente del tipo de anestesia:

- Los anestesiólogos y los asistentes necesarios deben implementar precauciones de gotas y contacto con protección para los ojos. El riesgo de un procedimiento médico generador de aerosol debe evaluarse para considerar las precauciones de EPP en el aire (bata, guantes y N95 con careta o respirador eléctrico purificador de aire (PAPR).

- Use listas de verificación para ponérselo y quitárselo, además de observadores capacitados. Doble guante para todos los procedimientos y reemplace la capa externa de guantes después de la intubación.

- Colocar el material requerido para la anestesia neuro- axial y para la anestesia general en bolsas para formar kits por separado listas para su uso.

7. En caso de anestesia general: todo el personal en el quirófano en el momento de la intubación debe tomar precauciones de EPP en el aire. Sólo el personal mínimo esencial durante la intubación: use su mejor criterio, mientras se asegura de tener alguna asistencia disponible.

- La oxigenación previa debe ocurrir con una extensión de circuito y un filtro en el lado del paciente del circuito.

- Use un circuito de sistema cerrado (jamás AMBU).

- La intubación debe realizarse por secuencia rápida, así como el uso de videolaringoscopía para maximizar el éxito en el primer intento y minimizar cualquier necesidad de proporcionar ventilación con máscara fácil y bolsa.

- La extubación es igualmente, si no es que más, un riesgo significativo; minimizar el personal, utilizar precauciones en el aire (N95/PAPR).

- Si decide continuar con la extubación al final del caso, extubar en el quirófano, mantener las precauciones en el aire hasta que el paciente esté listo para la transferencia. Considere los posibles riesgos y beneficios de transportar pacientes intubados a una sala de presión negativa (por ejemplo, UCI) para la emergencia/extubación.

8. Dado que la atención de un paciente con COVID-19, incluido el tiempo para ponerse y quitarse, requiere mucho tiempo, es posible que se necesite personal adicional y que se deban desarrollar estrategias de respaldo para cerciorarse de que se ponga y quite el equipo de manera adecuada.

9. Actualmente no hay información suficiente sobre la limpieza, el filtrado y la posible aerolización cuando se usa óxido nitroso en sistemas de analgesia en labor en el entorno de COVID-19, considerar suspender el uso.

10. Algunos expertos han sugerido evitar el uso de AINE para los síntomas sugestivos de infección por COVID-19; sin embargo, esto es controvertido y faltan datos sólidos. Se desconoce si el tratamiento del dolor posparto con AINE empeorará la evolución de los pacientes COVID +. Es probable que los AINE continúen utilizándose de manera segura en pacientes asintomáticos.

11. Se deben administrar antieméticos para prevenir el vómito en pacientes sometidos a cesárea. Sin embargo, debido a los riesgos potenciales de los esteroides en el contexto de la infección por COVID, considere evitar el uso de dexametasona para la profilaxis antiemética.

12. Tanto la anestesia epidural como subaracnoidea son seguras y efectivas para mujeres embarazadas y recién nacidos. Sin embargo, la incidencia de hipotensión parece ser significativamente mayor que lo normal durante la anestesia epidural.

13. No se recomienda el uso de carbetocina por el riesgo de broncoespasmo. 
14. No se recomienda el uso de opioides intravenosos en analgesia controlada por el paciente debido al riesgo de depresión respiratoria e instrumentación emergente de la vía aérea.

\section{ANESTESIA EN PACIENTES PEDIÁTRICOS CON SARS-COV-2/COVID-19}

\author{
Dr. Gabriel Mancera-Elías, \\ Dra. Alma Dolores Arenas-Venegas
}

A diferencia de los adultos la severidad del padecimiento puede ser menor y un par de factores que pueden influir: menor exposición al huésped y debido a la inmadurez de sus funciones la capacidad de enlace con la ACE2 (enzima convertidora de la angiotensina) que es receptor de SARS-CoV-2 sea menor que en el adulto.

El sistema inmunológico del paciente pediátrico se desarrolla con base en su grado de madurez, de tal manera que los lactantes pueden ser más susceptibles a la infección, aunque no existe diferencia significativa entre los grupos de edad.

El paciente COVID-19 que entra a quirófano o en algún escenario que requiere procedimientos anestésicos representan un riesgo para el equipo involucrado, particularmente los anestesiólogos debido al manejo de la vía aérea tanto en la instrumentación como en la ventilación a través de mascarilla o tubos de mascarilla, situaciones que incrementan la aerolización del virus y su consecuente dispersión. La Sociedad de Anestesia Pediátrica, la Colaboración de intubación difícil pediátrica y la Sociedad Canadiense de Anestesia Pediátrica publican en consenso unas guías de manejo de vía aérea en paciente, de cual se rescata lo siguiente:

1. Identificar y notificar adecuadamente acerca de los casos, la preparación de equipos y fármacos previos a la entrada del paciente a la sala, el personal médico que va a entrar debe abstenerse de equipo personal (reloj, celulares, plumas, etcétera).

2. La medicación preanestésica es recomendable, se busca cooperación en el caso de una vía intravenosa o disminuir la posibilidad de llanto y lucha en el caso de una inducción inhalada, la medicación preanestésica por vía nasal no es recomendable.

3. La inducción deberá ser de preferencia secuencia rápida. En el caso de la inducción por mascarilla tendrían que usarse flujos bajos. En el caso de instrumentación de vía aérea el acceso recomendado es mediante videolaringoscopía como primera opción mediante el anestesiólogo más experimentado, el uso de sondas endotraqueales con globo son las preferidas. La instrumentación deberá realizarse de preferencia con el uso de barreras transparentes de plástico.
4. El mantenimiento recomendado es por PPE aislando la vía aérea mediante barrera plástica, toallas o gasas húmedas. Deben utilizarse al menos dos filtros virales uno entre el circuito y la vía respiratoria y el otro al final de la rama espiratoria.

5. Durante la extubación se recomienda una línea cerrada, con paciente en plano suficiente para evitar tos, arqueo o expulsión violenta de secreciones. La recuperación se realiza en la sala de recuperación.

Adicionalmente a esta guía, la Sociedad Española de Anestesia y Reanimación (SEDAR) hace hincapié en algunos puntos extra:

Separación de quirófanos en área COVID-19 para casos confirmados o probables y otro para pacientes no sospechosos. El equipo de protección individual debe utilizarse en casos confirmados, sospechosos o probables sin confirmación, así como en casos de la clínica gastrointestinal de reciente aparición. Para estudios radiológicos se recomienda sedación profunda evitando en la medida de lo posible la instrumentación de la vía aérea. Al término de los procedimientos deberán recuperarse en el área y transportarse con colocación de mascarillas. Los pacientes intubados se reenviarán con ventiladores de transporte.

Las asociaciones Americana y Europea de Anestesia Regional (ASRA-ESRA) justifican el uso de las técnicas regionales al no tener la necesidad de utilizar mascarillas, ventilación con presión positiva y la posibilidad de tos con la subsecuente contaminación proponiendo el uso de técnicas centrales y periféricas con sedación moderada o profunda con puntas nasales de bajo flujo. El equipamiento recomendado es el estándar para paciente no COVID-19 y en casos positivos EPI, protección ocular, uso de mascarillas N95 y doble guante.

\section{ANESTESIA EN PACIENTES ONCOLÓGICOS CON SARS-COV-2/COVID-19}

\author{
Dr. Luis Felipe Cuellar-Guzmán, \\ Dra. Elvia Gabriela Villars-Zamora, \\ Dra. Nélida Mayorga-Castillo, \\ Dra. Luz Gabriela Franco-Padilla
}

\section{Cáncer y COVID-19}

Los pacientes con sistema inmunológico comprometido como es el caso del paciente oncológico son particularmente vulnerables, al igual que los que se someten a un tratamiento activo con quimioterapia o radioterapia, tienen mayor riesgo de desarrollar complicaciones graves por el virus, incluida la admisión a UTI o la muerte. La pandemia actual plantea 
tres problemas fundamentales de seguridad para el paciente con cáncer: en primer lugar, es más probable que se infecten debido a su estado inmunosuprimido relacionado con la enfermedad tumoral o el tratamiento contra el cáncer que están recibiendo y en segundo, los pacientes deben abandonar sus hogares para acudir al hospital y exponerse al contagio del virus. Se presentan con prueba confirmatoria en $7.8 \%$ comparado con $3.8 \%$ en la población total.

Liang y colaboradores publicaron en febrero de 2020 un cohorte de pacientes con cáncer durante el brote de COVID-19 en China, de un total de 1,590 pacientes COVID-19, (18 pacientes oncológicos), comparados con los pacientes sin cáncer, los pacientes con cáncer presentaron mayor riesgo de eventos severos siete (39\%) de 18 vs. 124 (8\%) de 1,572 pacientes $(\mathrm{p}=0.0003)$, los resultados eran peores en pacientes que habían recibido tratamiento activo durante el primer mes antes de la infección (75 vs. 43\%; OR 5.34), estos pacientes también tuvieron una rápido deterioro (13 vs. 43 días; $\mathrm{p}=0.0001$ ).

En abril de 2020, ASCO (American Society of Clinical Oncology) publica una serie de recomendaciones para mitigar el impacto del COVID-19 en pacientes oncológicos, recomendando la contención social con la asistencia virtual de pacientes controlados y de edad avanzada, comités de tumores y reuniones científicas deberán realizarse de manera virtual, priorizar y cambiar tratamientos médicos y quirúrgicos no curativos y cambio de terapia intravenosa a terapia oral, usar una selección estricta de pacientes que reciban quimioterapia intrahospitalaria (combinaciones de alta toxicidad con intento curativo), aquellos pacientes que ingresen al centro deberán someterse a protocolo COVID-19 (toma de temperatura corporal, inicio diagnóstico en caso de síntomas), optimizar medidas protectoras del personal de salud, estandarizar con las unidades de infectología, bioética y cuidados intensivos los criterios de entrada de pacientes de acuerdo a su pronóstico, incluir un registro para el cohorte de pacientes oncológicos positivos, para definir características clínicas, respuesta a tratamiento y resultados para poder refinar los protocolos institucionales.

\section{Cirugía en paciente con cáncer y COVID-19}

Considerando que el tratamiento del cáncer es impostergable, se hicieron sugerencias sobre el tratamiento de cada paciente individualizando los casos, comprendiendo la evolución de acuerdo al tipo de enfermedad neoplásica, priorizando etapa clínica, presencia de enfermedad a distancia y plan terapéutico establecido en procedimientos que no pueden ser diferidos. Actualmente ASCO en su página Web menciona cuatro guías para manejo de cáncer especifico (mama, hematológico, carcinoma hepatocelular, cirugía) publicadas por las diferentes sociedades, donde se sugiere cuáles procedimientos pueden ser diferibles temporalmente; asimismo la ESMO (European
Society of Medical Oncology) publica en su página un total de 16 guías de cáncer específicas donde se clasifican en alta, mediana y baja prioridad los diferentes tipos de manejo, incluyendo el quirúrgico. Se recomienda realizar un triage prequirúrgico, y prueba en casos sospechosos, el traslado del paciente al quirófano deberá realizarse de manera aislada, establecer un quirófano exclusivo (de preferencia con presión negativa), personal instruido y exclusivo para quirófano COVID-19, establecer áreas para colocación y para retiro de equipo de protección personal (bata impermeable, mascarilla N95 o FFP2/FFP3, gafas, pantalla de cobertura facial, gorro, guantes largos, calzado exclusivo) siguiendo los protocolos establecidos. Se recomienda intubación de secuencia rápida para evitar aerolización y el uso de videolaringoscopio. El manejo ventilatorio recomienda volúmenes bajos $4-8 \mathrm{~mL} / \mathrm{kg}$ peso ideal, presión meseta inspiratoria $<30 \mathrm{cmH}_{2} \mathrm{O}$, PEEP menor de $8 \mathrm{cmH} 2 \mathrm{O}$ y maniobras de reclutamiento cada 30 minutos. En el transoperatorio evitar procedimientos laparoscópicos, si se llevan a cabo evitar fugas por trocares, flujo bajo de CO2, presión baja de neumoperitoneo, y en el uso de cauterio, aspiración de humo quirúrgico.

\section{Anestesia multimodal a pacientes con cáncer con COVID-19}

Actualmente la anestesia multimodal ha tomado auge en el paciente oncológico, se ha descrito una gran cantidad de beneficios por la anestesia multimodal (anestesia regional combinada), dentro de los cuales destacan la preservación

\section{Cirugías que no pueden ser diferidas.}

Cáncer de mama

Enfermedad progresiva con terapia sistema, angiosarcoma o tumor filoides Cáncer colorrectal

Obstrucción, perforación y cirugía curativa en paciente sin metástasis Tumores endocrinos

Tiroides: con invasión local y alto riesgo de morbilidad, rápido crecimiento Enfermedad de Graves sin respuesta a tratamiento médico Obstrucción de vía aérea

Biopsia abierta con sospecha de linfoma o anaplásico

Adrenal: cáncer adrenocortical, feocromocitoma o paraganglioma, síndrome de Cushing con síntomas

Tumores neuroendocrinos de intestino delgado sintomáticos, tumores sintomáticos de páncreas y lesiones con crecimiento significativo

Gástrico y esofágico

Tumores de estroma gastrointestinal tumores sintomáticos o sangrantes Hepatopancreatobiliar

Malignidades agresivas: adenocarcinoma de páncreas, cáncer gástrico, colangiocarcinoma, cáncer duodenal, cáncer ampular, metástasis colorrectales a hígado

Melanoma

biopsia incompleta con lesión evidente

Malignidad superficie peritoneal

Obstrucción por malignidad y procedimientos paliativos

Sarcomas

Tumores lipomatosos altamente atípicos 
de la inmunidad celular y el manejo del dolor postoperatorio. Sui An Lie y colaboradores mencionan la posibilidad de que uso de anestesia regional con la principal ventaja en pacientes con COVID-19 sin síntomas respiratorios severos evitaría la instrumentación de las vías respiratorias y la tos del paciente durante la intubación y la extubación, y reduciría las complicaciones pulmonares postoperatorias, tomando en cuenta que el paciente debe usar una mascarilla quirúrgica en todo momento para evitar la transmisión de gotas. Si es necesario, se puede administrar oxígeno suplementario a través de puntas nasales debajo de la mascarilla quirúrgica para reducir la dispersión del aire exhalado que presenta un riesgo infeccioso. Si usa una máscara facial simple, el flujo de oxígeno debe mantenerse lo más bajo posible para mantener la $\mathrm{SpO} 2>92 \%$.

\section{ANESTESIA EN PACIENTES CARDIÓPATAS CON SARS-COV-2/COVID-19}

\section{Dra. Dania Elena Escamilla-Ríos, Dra. María Alejandra Minakata-Quiroga}

Debido a la contingencia, la mayoría de los centros cardiovasculares nacionales están realizando únicamente cirugías cardíacas urgentes y emergentes.

Los pacientes quirúrgicos sospechosos y confirmados que ingresen a cirugía deben ser tratados como casos positivos a COVID-19.

El factor tiempo no debe impedir un proceso meticuloso durante el perioperatorio, a continuación, se describen puntos clave en el manejo perioperatorio de pacientes quirúrgicos cardíacos.

\section{Preoperatorio}

Se debe evaluar si el cuadro de urgencia o emergencia está o no agravado por el COVID-19, definir con el equipo cardíaco

\begin{tabular}{|c|c|}
\hline \multicolumn{2}{|c|}{$\begin{array}{l}\text { Indicaciones para realización de cirugía } \\
\text { cardíaca de urgencia/emergencia }\end{array}$} \\
\hline Cirugías urgentes & Cirugías emergentes \\
\hline $\begin{array}{l}\text { Resolución quirúrgica en una a dos semanas } \\
\text { - Cardiopatía isquémica grave: } \\
\text { - Lesión de TCI } \\
\text { - SYNTAX elevado } \\
\text { - Estenosis aórtica severa sintomática } \\
\text { - Endocarditis izquierda con vegetaciones } \\
\text { grandes, móviles, condicionando lesión } \\
\text { valvular severa } \\
\text { - Aneurisma de aorta ascendente }>6 \mathrm{~cm} \\
\text { diámetro } \\
\text { - Insuficiencia mitral severa sintomática }\end{array}$ & $\begin{array}{l}\text { Resolución quirúrgica } \\
<24 \text { horas } \\
\text { - Disección aórtica aguda } \\
\text { tipo A } \\
\text { - Falla cardíaca aguda } \\
\text { secundaria a cardiopatía } \\
\text { isquémica o valvulopatía } \\
\text { - CIV postinfarto } \\
\text { - Disfunción valvular } \\
\text { protésica aguda }\end{array}$ \\
\hline
\end{tabular}

el proceso de toma de decisiones. Preparación anestésica: dos anestesiólogos cardíacos experimentados, un tercer anestesiólogo cardiovascular fuera de quirófano como apoyo, definir zonas semicontaminadas y zonas limpias, preparar sonda de ecocardiografía, ultrasonido lineal, monitores y máquina de anestesia para evitar contaminación de éstas, evaluar uso de BIAC (balón de contrapulsación intraaórtico), dispositivo de asistencia ventricular o ECMO (Extracorporeal Membrane Oxygenation).

\section{Intraoperatorio}

Colocar catéteres arteriales y catéter venoso central guiado por USG, intubación de secuencia rápida, en pacientes con baja reserva de oxigenación se podrá dar ventilación con presión baja con mascarilla facial y oxígeno suplementario a 100\%. Considerar que los pacientes con COVID-19 tienen daño miocárdico viral y está activado el sistema RAA, tener preparados vasopresores; está indicado el monitoreo hemodinámico invasivo para terapia de líquidos y uso de fármacos vasoactivos e inotrópicos. En pacientes con daño miocárdico agudo se debe considerar juiciosamente el uso de balón de contrapulsación intraaórtica, dispositivo de asistencia ventricular o ECMO. En pacientes con hipertensión pulmonar se recomienda infusión perioperatoria de dexmedetomidina, con los beneficios de extubación rápida, analgesia y sedación en el postoperatorio. Administrar fármacos que eviten náusea y vómito, posterior al cierre esternal descartar con USG pulmonar pneumotórax,

\section{Previo al ingreso del paciente}

- Verificar disponibilidad de EPP (respirador N95 o equivalente, goggles, careta, bata impermeable u overol, doble guante, gorro quirúrgico, botas quirúrgicas)

- Preparación de sala de operaciones, medicamentos cargados, circuito anestésico funcional, con filtro electrostático de alta eficiencia, sonda de ETE, sonda lineal, equipo de ultrasonido, monitoreo y videolaringoscopio preparado en sala

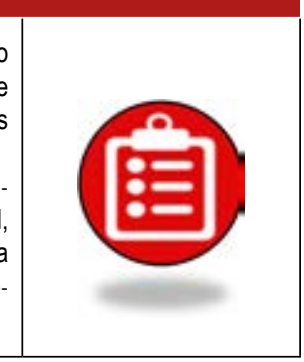


patología común en estos pacientes sometidos a ventilación mecánica.

\section{Postoperatorio}

El traslado de quirófano a terapia intensiva es crucial, antes de salir de quirófano se debe avisar al personal receptor, tener despejada ruta COVID-19, verificación de adecuada profundidad anestésica, adecuada perfusión de inotrópicos y fármacos vasoactivos. El personal debe quitarse la capa externa del EPP de acuerdo a protocolo institucional, y el personal que traslada al paciente debe usar EPP nuevo en la zona limpia, el ventilador portátil debe contar con los filtros de alta eficiencia y asegurarse de que no se desconecte el ventilador del tubo de forma accidental para evitar aerolización.

Existen otras condiciones no quirúrgicas, casos severos de COVID-19 en las que el equipo cardíaco se ve

\section{Abordaje de la vía aérea}

Todo el equipo
con EPP
colocado

Comprobar adecuada colocación con curva de capnografía ETCO${ }_{2}$, expansión simétrica del tórax, saturación de oxígeno

\begin{tabular}{|c|c|c|c|}
\hline Monitoreo & Consideraciones pulmonares & Consideraciones renales & $\begin{array}{l}\text { Manejo de componentes } \\
\text { sanguíneos }\end{array}$ \\
\hline $\begin{array}{l}\text { - Línea arterial } \\
\text { - Catéter venoso central } \\
\text { - ETE perioperatorio (fluidoterapia, } \\
\text { contractilidad, destete de CEC) } \\
\text { - Valorar necesidad de monitoreo } \\
\text { avanzado (catéter de arteria } \\
\text { pulmonar) }\end{array}$ & $\begin{array}{l}\text { Descartar neumotórax prequirúr- } \\
\text { gico mediante TAC } \\
\text { - Ventilación mecánica protectora } \\
\text { - } \quad \text { VT } 6 \mathrm{~mL} / \mathrm{kg} \text { peso predicho } \\
\text { - } \quad \text { Presión Plateau }<30 \mathrm{CmH}_{2} \mathrm{O} \\
\text { - } \quad \text { Titular PEEP para } \mathrm{SatO}_{2} \\
\quad 88-92 \%, \mathrm{pH}>7.25 \\
\text { - USG pulmonar para descartar } \\
\text { neumotórax antes de salir de } \\
\text { sala de operaciones }\end{array}$ & $\begin{array}{l}\text { - Fluidoterapia guiada por objeti- } \\
\text { vos (ETE) } \\
\text { - Alta incidencia de falla renal } \\
\text { aguda en COVID-19 } \\
\text { - Instaurar terapia de reemplazo } \\
\text { renal continua de manera } \\
\text { temprana en el perioperatorio si } \\
\text { amerita }\end{array}$ & $\begin{array}{l}\text { - Estrategias de conservación } \\
\text { sanguínea } \\
\text { - Hemodilución } \\
\text { - } \text { normovolémica } \\
\text { - Plasmaféresis } \\
\text { - Normotermia en CEC } \\
\text { - Recuperador celular } \\
\text { - Monitoreo de coagulación } \\
\text { - Recuento/función plaquetaria } \\
\text { - TP, TTPa, INR } \\
\text { - Tromboelastograma } \\
\text { Se prefieren concentrados de } \\
\text { factores a componentes sanguí- } \\
\text { neos por riesgo de TRALI }\end{array}$ \\
\hline
\end{tabular}

\section{Traslado al área de terapia intensiva}

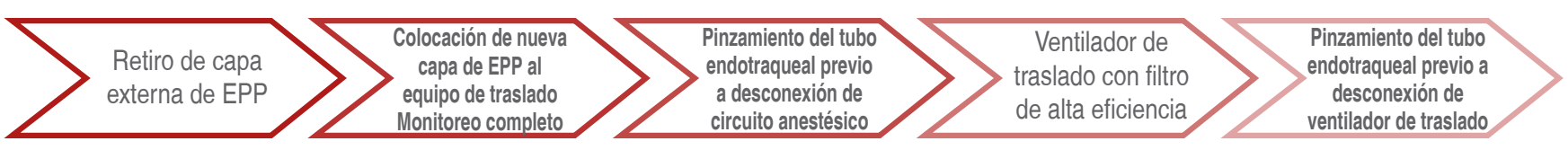

Ruta de traslado COVID previamente designada, especial atención a desconexiones de circuito de ventilador de traslado 
involucrado, algunos pacientes pueden presentar colapso cardiovascular por miocarditis, pericarditis, vasoplegia, falla ventricular derecha y síndromes coronarios agudos condiciones donde el tratamiento debe ser agresivo tanto médico como mecánico, y el equipo también debe discutir de forma multidisciplinaria y juiciosamente la colocación de ECMO considerando indicaciones, contraindicaciones, personal, equipo, instalaciones de atención y sistema de apoyo.

\section{ANESTESIA EN PROCEDIMIENTOS ENDOSCÓPICOS EN PACIENTES CON SARS-COV-2/COVID-19}

\section{Dr. José Manuel Portela-Ortiz, Dra. Delia Brenda Paola Ocampo-Valencia}

Está claramente demostrado que los procedimientos de control de la vía aérea y los que producen aerolización son factores de riesgo de contraer la infección por COVID-19. Los estudios endoscópicos de vías digestivas superiores, y en menor grado los de vías digestivas inferiores, conllevan ambos riesgos.

Es importante el mencionar que un porcentaje no despreciable de los pacientes COVID-19 cursan con síntomas gastrointestinales, siendo los más frecuentes, la anorexia, diarrea y dolor abdominal, por lo cual podrían ser referidos al Servicio de Endoscopía. Además, existe la duda por el momento del grado de infectividad, y el tiempo posterior a la desaparición de los síntomas en que las heces fecales continúan siendo un riesgo de infección.

En apartados previos de esta guía se han mencionado precauciones y procedimientos que deberán llevarse a cabo en el manejo y control de la vía aérea, así como el tipo y utilización eficiente y eficaz del equipo de protección personal. A continuación, se exponen algunos conceptos útiles en las salas de endoscopía.

La protección del personal sanitario inicia con la aplicación de medidas administrativas, empezando con la reprogramación de los estudios endoscópicos.

Estos deberán catalogarse en urgentes, prioritarios y electivos, debiendo reprogramarse las últimas dos categorías. Los pacientes que requieran estudios, intubados o inestables hemodinámicamente, no deberán ser trasladados por el riesgo que representan para ellos y los procedimientos se realizarán en las unidades de terapia intensiva.

En el Área de Endoscopía, de contar con una sala de presión negativa, será la que deberá utilizarse, y de no contar con ésta, se abstendrá de utilizar el aire acondicionado para no difundir los aerosoles generados. De preferencia se programarán los estudios de los pacientes confirmados o sospechosos al final del turno.

Si se decide programar casos electivos, se contactará al paciente el día previo para aplicar un interrogatorio y detectar datos de alarma que cancelen su estudio. A su ingreso todos los pacientes se reinterrogarán y se les tomará la temperatura. No se permitirá el paso de los familiares al área, y todos los trabajadores sanitarios portarán cubrebocas de tipo quirúrgico y mantendrán el distanciamiento apropiado. Para fines prácticos, todos los pacientes en la fase 3 de la pandemia se considerarán posibles portadores de COVID-19 debido a la existencia de portadores asintomáticos infectantes que constituyen una fuente importante de contagio.

Por tratarse de procedimientos productores de aerolización, todo el equipo sanitario que intervenga en el procedimiento deberá utilizar equipo personal de protección completo.

Deberá incluir: gorro, bata impermeable, protección ocular tipo goggles o máscara facial, doble guante, botas protectoras y cubrebocas N95. Tendrán capacitación previa para la instalación y el retiro del equipo siguiendo una guía escrita. La recuperación de los pacientes COVID-19 o sospechosos deberá llevarse a cabo en la misma sala de endoscopía, y en los picos de la pandemia se aplicará esta medida a todos los pacientes.

La evidencia actual para estas recomendaciones es baja, debido a la mala calidad metodológica de los estudios, el bajo número de pacientes, y la escasez de estudios. Pero creemos que son las mejores basadas en el principio de precaución. Recordemos que COVID-19 es una enfermedad más trasmisible que la influenza, y que el personal sanitario tiene un riesgo tres veces mayor de resultar contagiado. Es nuestra responsabilidad ayudar a evitar que nuestro sistema de atención médica se vea saturado aplanando la curva de casos lo más pronto posible. 


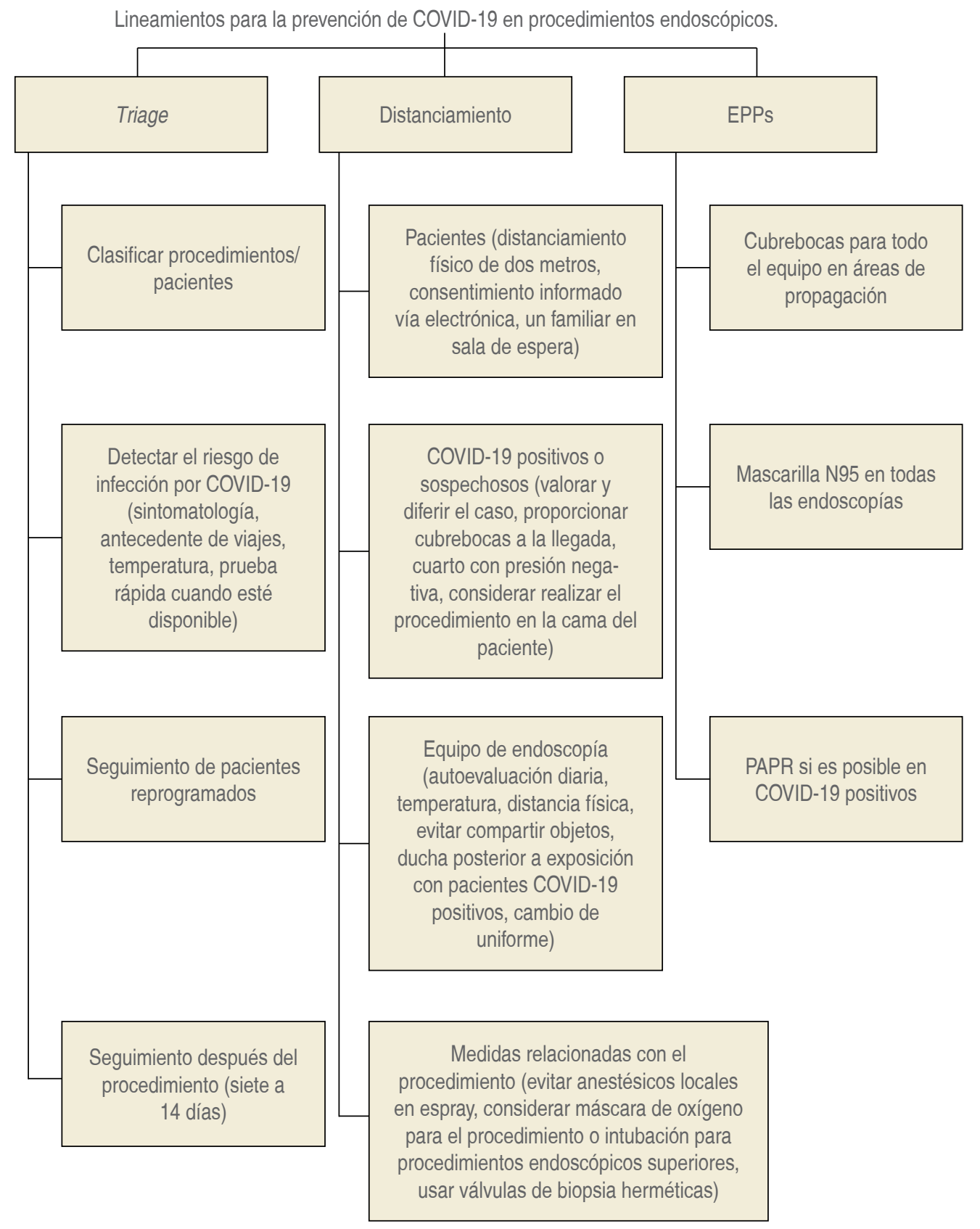

\section{SEDACIÓN DE LOS PACIENTES CON SARS-COV-2/COVID-19}

\section{Dra. Dolores Pérez-Pérez}

El síndrome de distrés respiratorio grave asociado a la infección por COVID-19 precisa sedación profunda para conseguir adaptación al respirador y maniobras de reclutamiento, en quirófano prácticamente no se recomienda la misma debido a la baja reserva pulmonar que presentan estos pacientes.

La sedación debe ser dinámica y secuencial, dirigida por objetivos, individualizada, monitorizada mediante monitorio convencional no invasivo, agregando ETCO2, índice biespectral (BIS) y tren de cuatro (TOF), y adaptada a la situación clínica del paciente, sólo en casos específicos se aplica monitorización invasiva con línea arterial y acceso central. Considerar si el paciente se encuentra con tratamien- 
to antitrombótico, pruebas de función hepática y presencia de lesión renal aguda.

La sedación excesiva causa efectos perjudiciales a corto y largo plazo. Se debe prevenir el delirium y favorecer la movilización precoz.

No retrasar el apoyo ventilatorio invasivo. Intubación por el profesional mejor calificado, por dos personas, con intubación de secuencia rápida con caja de plástico transparente y videolaringoscopio, con rocuronio $(1.2 \mathrm{mg} / \mathrm{kg})$ y etomidato $(0.2-0.3 \mathrm{mg} / \mathrm{kg})$ o ketamina $(1.5 \mathrm{mg} / \mathrm{kg})$ de forma casi simultánea. De ser necesario agregar un inductor tipo midazolam o propofol a dosis bajas. No se debe realizar intubación con paciente despierto bajo fibroscopía ni nebulización de anestésico local en vía aérea.

La elección de la técnica anestésica depende de los síntomas respiratorios del paciente y del tipo de intervención, se recomienda evitar la anestesia general y optar por anestesia regional. En caso de requerir resucitación cardiopulmonar sólo se dan compresiones.

Considerar interacciones farmacológicas con los tratamientos a través de www.covid19-druginteraction.org.

Mantener BIS entre 40-60 para acoplamiento al respirador, de 60 a 80 para destete mediante reducción de fármacos de mayor vida media como midazolam y sustitución por aquéllos con vida media menor como propofol, remifentanilo o dexmedetomidina.

Los bloqueadores neuromusculares con menos interacciones farmacológicas con los tratamientos usados son cisatracurio y vecuronio. Para minimizar el número de intervenciones, se recomiendan infusiones continuas con monitorización mediante TOF y el menor tiempo posible, de preferencia no más de 48 horas.

Se debe evitar el uso prolongado de opioides, nefrotóxicos, almidones, corticosteroides y antibióticos de primera instancia. Manejar analgesia multimodal con otro tipo de analgésicos diferentes de los opioides como paracetamol, AINES y metamizol.

La retirada de la sedación y destete de la ventilación mecánica puede ser difícil por la agitación y el delirium, monitorizar mediante escalas como el CAM-ICU o ESCID. Evitar fármacos como quetiapina y ziprasidona debido a que potencian el alargamiento del QT, siendo una opción más segura la dexmedetomidina. Debe tenerse precaución con el uso de haloperidol por las interacciones farmacológicas. En casos de agitación no controlada con riesgo de extubación accidental la traqueotomía precoz sería una estrategia eficaz.

\section{TRASLADO INTRAHOSPITALARIO DEL PACIENTE CON SARS-COV-2/COVID-19}

\author{
Dra. Diana América Fernández-Martínez
}

La correcta coordinación del traslado intrahospitalario del paciente requiere la existencia de un plan de comunicación en el que se defina el circuito de avisos y alertas previos para preparar anticipadamente todo el operativo del traslado y recepción del paciente con COVID-19. Se deben implementar en la medida de lo posible circuitos exclusivos, contemplando escenarios posibles a/desde: ingreso a urgencias; planta; servicios de emergencias sanitarias; Unidad de Cuidados Intensivos; quirófano; etc. siguiendo medidas de protección y control de la infección necesarias para tratar de evitar la diseminación.

Se recomienda para el traslado intrahospitalario que el vehículo de transporte cuente con una cabina o cámara de conducción aislada. Siguiendo medidas de aislamiento, protección individual y desinfección establecidas entre el personal y el paciente antes de ingresar en una habitación aislada con presión negativa, si se dispone de ella.

Cada hospital deberá establecer su propio procedimiento específico de aislamiento.

Durante su traslado e ingreso a sala, el paciente debe usar una mascarilla facial. Durante la intervención las puertas de quirófano permanecerán herméticamente cerradas, permaneciendo en su interior sólo el personal mínimo requerido, el cual llevará el EPP correspondiente.

\section{Traslado del paciente a sala de quirófano}

El traslado al quirófano se realizará con las medidas de precaución descritas para el personal sanitario (EPP) utilizando circuitos de traslado exclusivos o con poco tránsito.

\section{Pasos a seguir:}

1. El cirujano se comunicará con el personal de quirófano para dar instrucciones claras del procedimiento a realizar y/o alternativas con el fin de contar con todos los insumos necesarios en el acto quirúrgico, minimizando los movimientos lo máximo posible. Asimismo, el equipo de anestesiología se comunicará con el personal de enfermería en quirófano para informar cuál es el material necesario para la realización de la técnica anestésica.

2. Se preparará todo el material necesario para el traslado (monitor de traslado, ventilador portátil, de preferencia circuito doble ramal y de un solo uso con filtros inspiratorios y espiratorios de alta eficiencia, medicación y material de emergencia).

3. Se prepara el quirófano específicamente destinado a estos pacientes con lo necesario para el procedimiento.

4. La transferencia del paciente a la sala de quirófano estará a cargo de las enfermeras de la unidad de origen de éste y del personal del servicio de camillería, así como 
el médico a cargo del paciente, todos con el EPP correspondiente (gorro, bata impermeable de aislamiento desechable, protección respiratoria FFP2 o FFP3, si se dispone, protección ocular y/o máscara facial desechable, guantes desechables). Para los pacientes que vienen de cuidados intensivos bajo ventilación mecánica, se utilizará un ventilador de transporte de uso exclusivo para estos pacientes. Debe permanecer el humidificador/filtro inmediatamente posterior al tubo endotraqueal.

5. El inicio del traslado intrahospitalario se comunicará al servicio receptor.

6. Si es necesario el ascensor, éste quedará bloqueado para la realización del traslado y su posterior desinfección. Se recomienda designar un ascensor de uso exclusivo.

7. El personal de seguridad precederá al equipo de traslado a la distancia de seguridad recomendada para desalojar la zona desde la unidad de origen hasta el quirófano, portando mascarilla quirúrgica.

8. El personal de limpieza tras el paso del equipo de traslado realizará la desinfección de las zonas transitadas durante el mismo.

9. Se entregará al paciente en su cabina de aislamiento al personal receptor de quirófano. Una vez finalizado el traslado, los operadores (médico, enfermería y camillero) procederán a retirar la camilla de traslado y luego de retirarse el EPP en el lugar designado, procederá la limpieza de la camilla por el personal de limpieza.

10. El paciente será recibido por el equipo de anestesiología, equipo de enfermería de la sala de quirófano y camillero dentro del quirófano por la entrada designada (transfer), quienes pasarán a colocar al paciente en sala.

Dentro del quirófano permanecerán solamente el personal imprescindible:

- Dos o tres anestesiólogos: permaneciendo uno o dos dentro de la sala y el tercer anestesiólogo permanecerá fuera del quirófano observando y apoyando al equipo de anestesia que se encuentre dentro (registros, trámites, etcétera).

Si el paciente viene con ventilación mecánica, para evitar la aerolización, en el momento de conectarlo al ventilador de la máquina de anestesia, el flujo de gas se cierra y el tubo endotraqueal se sujeta con pinzas durante el cambio de ventiladores dentro del quirófano. Durante el procedimiento, personal del equipo de enfermería circulante externo y personal del equipo de anestesiología externo se encontrarán fuera del quirófano, si se necesitan medicamentos o equipos adicionales; este proceso se utiliza para enviar muestras de sangre, gases, etcétera.

11. El resto del personal esperará vestido con el EPP correspondiente fuera del quirófano hasta salir el paciente. El tercer anestesiólogo y personal del servicio de traslado (camillero) permanecerán fuera de la sala. El camillero permanecerá dentro de quirófano hasta que la cirugía haya empezado o hasta que ya no sea necesaria su presencia. En este momento se sacará la camilla del paciente sin ropa y se dejará en la puerta del quirófano para su desinfección.

\section{Traslado del paciente de sala de quirófano a unidad de destino}

1. Al finalizar la intervención quirúrgica, siguiendo las recomendaciones, la recuperación del paciente se realizará en quirófano (evitando estancia en otro lugar); una vez cumplido el tiempo de permanencia necesario para garantizar la seguridad del paciente durante el traslado y estancia en piso, se proseguirá a realizar el traslado. Cuando el paciente está listo para el alta, se despeja nuevamente por seguridad la ruta a la sala de aislamiento destino. Se planifica un mínimo de una hora para permitir que el personal de quirófano envíe al paciente de vuelta a la sala de destino, y se realice la descontaminación de las superficies.

2. La enfermera circulante comunicará al servicio correspondiente de destino del paciente, y el material con el que se traslada (ambú, equipos de bomba intravenosa, medicamentos, etc.) para que se tenga listo al momento de su llegada.

3. Para evitar circulación excesiva e innecesaria, se avisará al camillero con su EPP correspondiente para entrar al quirófano por el paciente y se realizará el traslado directamente al servicio correspondiente (hospitalización, urgencias, UCI).

4. El traslado del paciente debe ir acompañado por un camillero; el anestesiólogo correspondiente (anestesiólogo que permaneció fuera de sala y/o segundo anestesiólogo operador dentro de sala); enfermera circulante (que permaneció fuera de sala), todos con su EPP adecuado.

5. Se entregará al paciente en la unidad de destino. El personal de traslado (camillero, anestesiólogo, enfermería) regresarán de forma inmediata sin realizar paradas al quirófano para la retirada del EPP en el área designada, siempre bajo la supervisión de otra persona y de uno en uno.

6. Para el traslado del paciente bajo ventilación mecánica, él médico a cargo del traslado (anestesiólogo), se hará cargo de la vía aérea al momento del traspaso. Una vez posicionado sobre la cama en terapia intensiva, hospitalización, urgencias, etc., y conectado a un monitor multiparamétrico se deben retirar los operadores con EPP (enfermería y camillero). Posteriormente se procederá al paso de la ventilación mecánica desde el ventilador de traslado al ventilador de la unidad. Pausando la ventilación del ventilador de tras- 
lado, pinzamiento del tubo orotraqueal, desconexión de la tubería a la altura del tubo Y, previo al filtro y se conecta a el ventilador de la unidad.

En la protección del personal sanitario es prioritario disponer del equipo de protección necesario durante su traslado. Si se generaron aerosoles durante la cirugía (corte de hueso, etc.): se recomienda al personal de traslado uso de mascarillas FFP2 o FFP3. En el paciente que precise de oxigenoterapia durante su traslado, se debe evitar el uso de aerosoles, gafas nasales de alto flujo o ventilación no invasiva en la medida de lo posible. Se le pondrá una mascarilla quirúrgica por encima de la mascarilla facial utilizada o cánulas nasales de oxígeno para su oxigenoterapia. Por último, se realizará un registro de cada uno de los profesionales que han entrado en contacto con el paciente, a efectos de control y seguimiento.

\section{Sitio de desconexión de tubería para traslado}

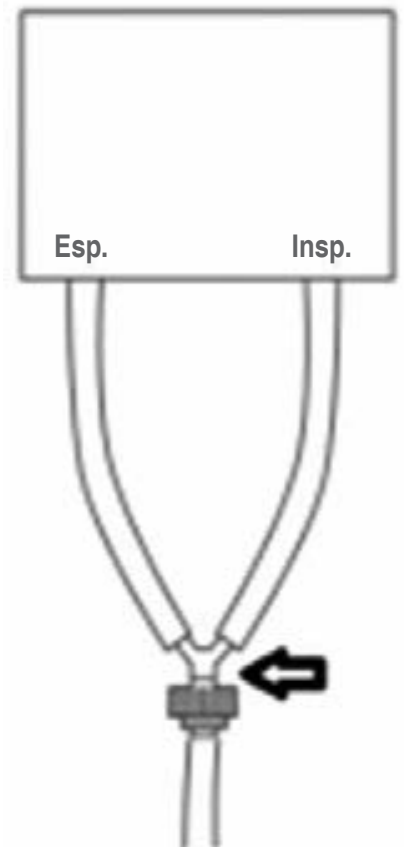

Equipo necesario para el traslado.

Equipo Equipo de vía aérea (bolsa-máscara, caja de traslado) Tanque de $\mathrm{O}_{2}$ lleno (en zona verde)

Medicamentos de resucitación y sedación (en caja de traslado)

Fluidos para infusión IV

Bombas adecuadas para traslado

Ventilador de traslado

Cabina o cámara aislante de traslado (recomendable)

\section{Cuidados durante el traslado}

Los operadores deben procurar evitar cualquier contacto con superficies ajenas al paciente, camilla y dispositivos de traslado (botones, ascensor, puertas). El personal de seguridad responsable de despejar las áreas será el indicado para seleccionar el piso de acuerdo a la ruta de traslado establecida. El camillero debe permanecer en el extremo contrario a la cabecera del paciente (ver diagrama en la siguiente página).

\section{RECONVIRTIENDO EL QUIRÓFANO DURANTE LA PANDEMIA DE COVID-19}

\section{Dr. Mario Suárez-Morales, Dra. Cecilia Úrsula Mendoza-Popoca}

El SARS-CoV-2 (COVID-19) se disemina por la transmisión de humano a humano a través de la exposición a microgotas provenientes del aparato respiratorio infectado o mediante transferencia por contacto con superficies contaminadas (fómites).

El virus puede permanecer en diferentes superficies de dos a ocho horas (aluminio) hasta cinco días (cerámica y teflón).

La posibilidad de tomar las precauciones necesarias para que entre los trabajadores de la salud en general y los anestesiólogos en particular se logre limitar la transmisión e infección por el virus es una tarea prioritaria y de máxima importancia.

Una de las consideraciones más importantes cuando se presenta la necesidad de intervenir quirúrgicamente a un paciente con sospecha o diagnóstico de COVID-19 es prevenir a toda costa la aparición de infecciones cruzadas en la sala de quirófano mediante la implementación de procedimientos de control de infecciones.

A continuación, se enuncian las recomendaciones propuestas para conseguir este objetivo:

- Idealmente se debe contar con una sala quirúrgica (SQ) con aislamiento de infección por vía aérea. Las SQ por defecto y lineamientos establecidos para su planeación deben contar con filtros tipo HEPA (High Efficiency Particulate Arresting) de alta eficiencia, los cuales son capaces de extraer del aire partículas $>0.3 \mu \mathrm{m}$ de diámetro con una eficiencia de $99.97 \%$.

- Una SQ ya existente se puede convertir en este tipo de sala aislada (Sala COVID-19) mediante la creación de presión negativa con el fin de reducir la diseminación del virus. Lo anterior se logra extrayendo, por el ducto de salida de aire, más aire que el que se suministra. Debe ser a la vez sellada para que no haya escape de aire por otras vías. Lo 
Protocolo del circuito de traslado intrahospitalario del paciente. COVID-19

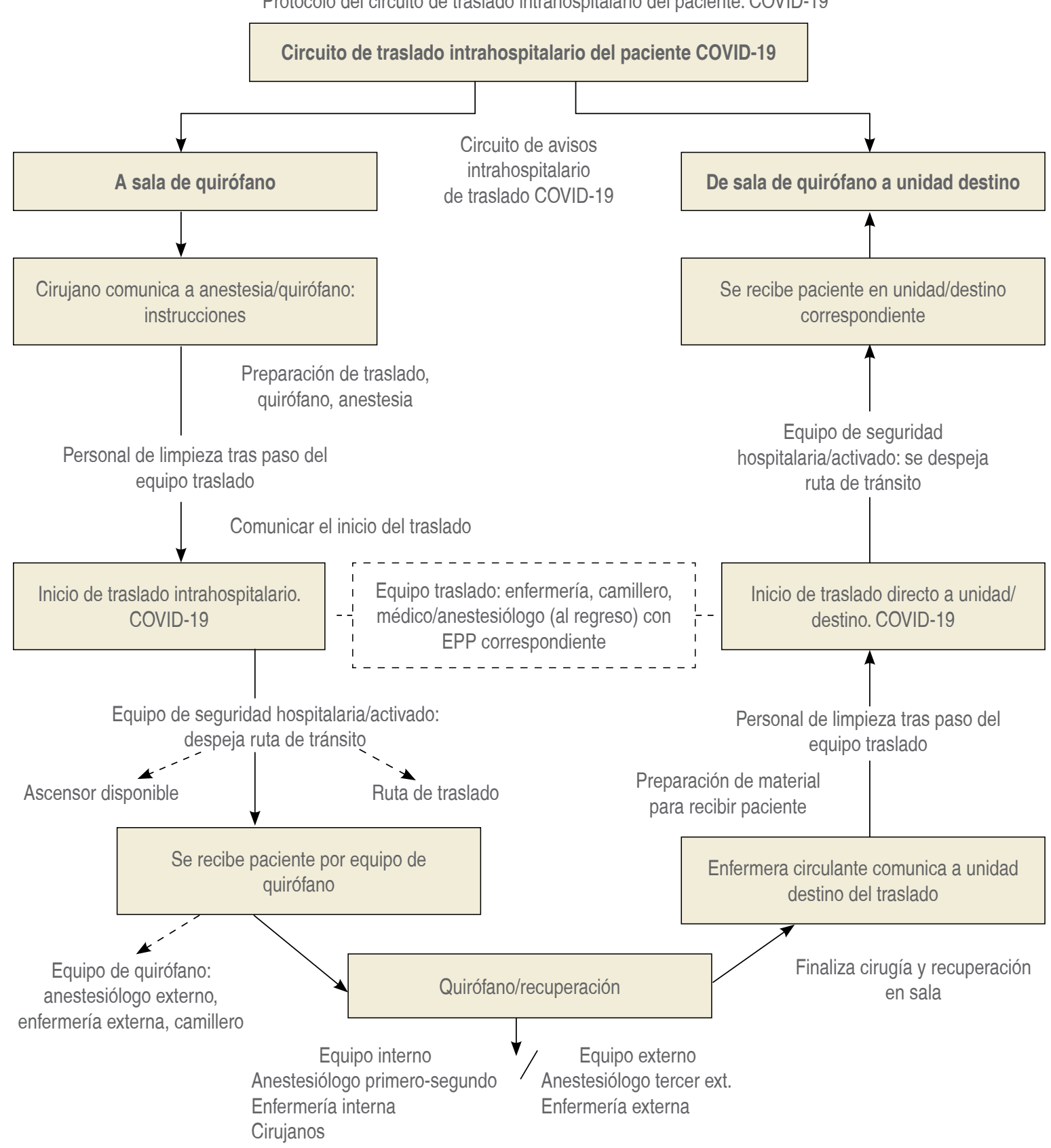

anterior tendrá que ser efectuado por el personal de Ingeniería Biomédica o quien se encargue de la regulación de estos parámetros.

- Los sistemas de ventilación con los que se provee a las SQ están diseñados para que por lo menos brinden 10 recambios de aire por hora. Con el fin de optimizar la seguridad en la SQ la ventilación debe llevarse a una frecuencia de cuando menos 12 recambios de aire por hora e idealmente 20 . El primer recambio de aire desaloja aproximadamente 63\% del virus, después del segundo permanece en la SQ $14 \%$, mientras que cuando se alcanza el quinto recambio queda $<1 \%$ de la carga viral original.

- Si es posible, se aconseja hacer una antesala adyacente a la entrada de la SQ lo más hermética posible, proveyéndola de una puerta que debe cerrarse antes de abrir la de la SQ. Ésta debe contar con presión positiva con respecto a la SQ.

- La entrada de la SQ debe ser señalada claramente como: Sala COVID-19. 
- El control de tráfico de entrada y salida de la sala debe disminuirse al máximo y las puertas deben mantenerse cerradas en el curso de la cirugía.

- Debe realizarse desinfección y esterilización de la máquina de anestesia y de toda la SQ utilizando soluciones de hipoclorito de sodio a 1,000 ppm.

- El mobiliario quirúrgico debe reducirse a lo mínimo indispensable.

- Se debe limitar al máximo posible la cantidad de personas dentro de la SQ. Se propone el siguiente personal: dos anestesiólogos, una enfermera instrumentista, una enfermera circulante y cirujanos mínimos necesarios. Debe restringirse la presencia de médicos residentes.

- Afuera del quirófano y en espera, se encontrará un tercer anestesiólogo quien hará los registros pertinentes, apuntes o llamadas telefónicas que sean necesarias.

- Se preferirá siempre el uso de equipo desechable cuando sea posible.

- Los monitores, la máquina de anestesia, el equipo de ultrasonido, y las mesas se cubrirán con una envoltura de plástico lo más hermética posible.

- Al término de la cirugía se desecha todo el equipo de cobertura y de uso único. El resto de los instrumentos se envían a proceso de descontaminación y esterilización.

Los participantes en la cirugía deben bañarse inmediatamente después.

- Si el paciente no necesita ser trasladado a la UCI se quedará en el quirófano en el postoperatorio inmediato recuperándose alrededor de una hora de donde pasará directamente a su habitación por la ruta de pasillos señalada para este efecto.

- Se ha establecido la necesidad de esperar al menos una hora entre casos con el fin de descontaminar todas las superficies, pantallas, teclados, monitores y la máquina de anestesia.

- Además de la limpieza manual de la SQ se recomienda fuertemente el uso de un vaporizador de peróxido de hidrógeno.

\section{SANITIZACIÓN DE LA MÁQUINA DE ANESTESIA DURANTE LA PANDEMIA DE COVID-19}

\section{Dr. Mario Suárez-Morales,}

\section{Dra. Cecilia Úrsula Mendoza-Popoca}

- Para evitar la contaminación de la máquina de anestesia (MA) se debe colocar un filtro viral de alta calidad entre el circuito y la vía aérea del paciente, de preferencia HME (Heat and Moisture Exchange).

- Si no se dispone de HME, usar el filtro disponible, pero con flujos bajos.
- Colocar un segundo filtro al final de la rama espiratoria en la conexión a la MA y de ser posible agregar otro filtro a la rama inspiratoria.

- En caso de sospecha de alguna disfunción de los filtros anteriormente mencionados se deberán limpiar y desinfectar con hipoclorito de sodio al $0.5 \%$ o alcohol isopropílico al $70 \%$, las válvulas direccionales, la válvula de sobrepresión, el contenedor del canister y el sistema respiratorio de la MA.

- Los fuelles respiratorios una vez desmontados junto con su empaque pueden ser desinfectados con glutaraldehído al $2 \%$.

- Usar siempre que sea posible circuito desechable y con mínimo espacio muerto.

- Administrar el mínimo volumen corriente.

- Cambiar la trampa de agua del capnógrafo y su sistema acompañante.

- Ante la sospecha y/o confirmación de un paciente COVID-19 cambiar todo, incluida la cal sodada para la absorción de CO2.

- Los monitores, cables y sensores deben limpiarse con alcohol isopropílico (70-99\%).

- Si se siguen los lineamientos anteriores con respecto a la protección de la MA se minimizan al máximo posible el riesgo de infectar a pacientes subsecuentes.

\section{PAPEL DEL ANESTESIÓLOGO EN LA REORGANIZACIÓN DEL QUIRÓFANO DURANTE LA PANDEMIA DE COVID-19}

\section{Dr. José Adolfo Islas-Velasco}

Próximamente se espera un alza importante en el número de casos infectados, por lo que el anestesiólogo debe estar preparado en la reorganización del quirófano para abordar a este tipo de pacientes tanto en casos de cirugía electiva como en emergencias quirúrgicas, así como ser un experto en el manejo de la VA (vía aérea) puede requerirse para apoyar otras áreas críticas como el Servicio de Urgencias o la UCI.

Es esencial en estos momentos establecer guías o protocolos para el manejo en anestésico-quirúrgico de estos pacientes en quirófano y crear un comité para definir, comunicar responder e implementar el mejor manejo en el hospital donde desarrollamos nuestras actividades, de acuerdo a los recursos disponibles. El objetivo es actuar oportuna y profesionalmente para cuidar y proteger a los pacientes y al personal intrahospitalario involucrado. Hoy en día nos vemos beneficiados de las lecciones y experiencias de otros grupos alrededor del mundo para planear nuestro desempeño en quirófano.

\section{Protocolo anestésico en quirófano}

Factor humano: el personal hospitalario que interviene en el traslado y durante la intervención quirúrgica debe ser 
el mínimo posible para disminuir el riesgo de contagio. Se requiere el menor número posible de cirujanos necesarios para la intervención. Un médico anestesiólogo responsable de la anestesia, el cuál permanecerá en contacto más próximo con el paciente, administra medicamentos y es el profesional más experimentado en el manejo de la VA, además de una enfermera o un TTR de apoyo, sin contacto con el paciente, que le asistirá continuamente, cargando los medicamentos necesarios, preparando el equipo de intubación completo y el ventilador, o en su caso el equipo de bloqueo regional. Se recomienda utilizar un videolaringoscopio. Habrá una enfermera circulante y una instrumentista. Fuera del área de quirófano podrá estar otra enfermera más auxiliando en las necesidades de abasto que puedan surgir.

El quirófano: debe quedar cerrado durante toda la intervención, y tiene que estar preparado con antelación para recibir a este tipo de pacientes. El personal debe retirar todo tipo de elementos innecesarios en esos momentos. Señalar en las puertas que el acceso está prohibido. Se requieren contenedores específicamente diseñados y protegidos con solución desinfectante para depósito de material reciclable (cubrebocas, batas, goggles, caretas, etc.). Colocar el carro de medicación fuera del quirófano. Es básico proteger la máquina de anestesia y los aparatos de monitorización o quirúrgicos, con cubiertas con fundas de plástico trasparente que permitan su empleo sin contacto directo. Asegurar la disponibilidad de soluciones de gel alcoholadas, y colocar filtros biológicos en las ramas inspiratoria y espiratoria del circuito anestésico, el vaporizador lleno, la cal sodada limpia, y en caso necesario solicitar cualquier sistema de monitorización extra según el paciente.

Manejo de la vía aérea: la protección personal es prioritaria. Se deben extremar las precauciones para el manejo del paciente, el aislamiento y el contacto, antes de iniciar el manejo de la VA. Se necesitan dos personas para la intubación. Limitar el número de participantes. El equipo personal de protección especial (PPE) es obligatorio. El personal implicado debe estar capacitado en la adecuada colocación y retiro del equipo de protección según el protocolo preestablecido de 10 pasos. El equipo de protección personal consta de: mascarilla de alta protección (N95), protección ocular integral (goggles), y/o protector facial completa (careta), uso de doble guante, botas y bata impermeable desechable. Se recomienda preparar y tener disponible un kit completo con el material necesario para la intubación y la protección de las dos personas involucradas en el proceso.

Todo el equipo usado en el manejo de la VA y el material de protección personal (PPE) debe considerarse altamente contaminante, y tiene que ser desechado de manera correcta al finalizar la intubación o el acto anestésico. Al final de la cirugía se procederá a la limpieza del quirófano, y del área y estructuras donde se haya realizado la intubación según el protocolo habitual hospitalario de desinfección.
La ASA ha recomendado para el manejo anestésico en quirófano de pacientes con COVID-19, reducir o posponer las cirugías o procedimientos intervencionistas electivos, priorizar los casos de coronavirus, adecuar correctamente el ambiente de trabajo haciendo énfasis en el manejo de la VA y en el mantenimiento de las máquinas de anestesia, también recomienda no usarlas en pacientes en terapia intensiva, a menos que se vea rebasada la capacidad instalada de ventiladores en el hospital. El empleo de una técnica neuroaxial se hará con la protección adecuada para el paciente y para el personal involucrado. Se insiste constantemente en la importancia de utilizar el equipo personal de protección (PPE).

\section{IMPLICACIONES BIOÉTICAS EN ANESTESIOLOGÍA DURANTE LA PANDEMIA DE COVID-19}

\section{Dra. Maricruz Pérezamador-del Cueto}

La Organización Mundial de la Salud declara la pandemia de COVID-19 el 11 de marzo de 2020 debido a la propagación del virus en 114 países. Recomienda que: «todos los países deben buscar un buen equilibrio entre proteger la salud, minimizar los efectos adversos en la economía y la sociedad y respetar los derechos humanos» en situación grave o crítica.

Hay un desequilibrio entre los recursos sanitarios disponibles y la cantidad de enfermos que los requieren. En una emergencia de salud el objetivo es tratar al mayor número de pacientes y salvar la mayor cantidad de vidas.

La escasez de recursos y la falta de tratamiento específico nos enfrenta a dilemas éticos como la asignación justa de los ventiladores mecánicos, el retiro de medidas de soporte y seguridad del personal de salud.

Aceptar los límites de la medicina es uno de los mayores dilemas éticos.

Es lícito renunciar a medidas desproporcionadas y cambiarlas por medidas de confort.

Es lícito interrumpir los tratamientos cuando resultan fútiles o desproporcionados.

Es útil orientarse por algunos puntos a evaluar antes de iniciar o suspender un tratamiento:

1. Determinar los fines que se buscan y con qué medios se harán, considerando los riesgos y evaluando lo que es deseable contra lo que es posible, lo que es seguro contra lo que es probable.

2. Evaluar los efectos positivos del tratamiento en cuanto a resultados, así como las potenciales secuelas o desenlace.

3. Analizar cuál es el mal menor o la decisión correcta entre dos situaciones igualmente buenas o igualmente malas.

4. Realizar la acción si el resultado es bueno o indiferente y con la intención de mitigar el mal. 
Toda persona tiene autonomía y cuando se encuentra en alguna situación de incapacidad intelectual o en estado de inconsciencia su autonomía radica en su tutor o representante legal. Se debe respetar la autonomía de los pacientes que ingresan por COVID-19 manteniendo la integridad y seguridad del equipo tratante. La intervención debe ser de acuerdo a lo autorizado en el consentimiento informado, que es la decisión libre y voluntaria que acepta las acciones diagnósticas o terapéuticas sugeridas por sus médicos, fundada en la comprensión de la información revelada respecto a riesgos y beneficios que pueden ocasionar (Ley General de Salud artículos 100, 323 y 324). El médico debe informar de una manera clara el diagnóstico, pronóstico, posibles riesgos y beneficios (NOM-168-SSA-1998). Todo sujeto es dueño y responsable de su salud y las decisiones que tome son de su incumbencia exclusiva, siempre que no afecte a terceros. Es recomendable que el paciente que no acepta un tratamiento firme su decisión.

La voluntad anticipada es la decisión que toma una persona de ser sometida o no a medios, tratamientos o procedimientos médicos que pretendan prolongar su vida cuando se encuentre en una etapa terminal y por razones médicas sea imposible mantenerla de forma natural, protegiendo en todo momento la dignidad de la persona. Posiblemente estamos en un momento de hacerla de uso habitual para facilitar las decisiones médicas y evitar el ensañamiento terapéutico en esta situación de emergencia.

\section{IMPLICACIONES LEGALES EN LA ATENCIÓN Y MANEJO ANESTÉSICO DE PACIENTES CON COVID-19}

\section{Dra. Ruth Martínez-Isarraraz \\ Dr. Manuel Alejandro Vázquez-Flores}

\section{Introducción}

La pandemia de COVID-19 tiene su importancia en el ámbito médico, deriva de su alta contagiosidad debido a su medio de trasmisión por aerosoles al ser inhalados o al tener contacto con superficies contaminadas, actualmente es un problema de salud pública.

Derivado de lo anterior el personal de salud encargado de la atención de estos pacientes son la parte más vulnerable de adquirir esta enfermedad, por lo que requieren de equipos de protección adecuados para su protección personal y disminuir el riesgo de contagio y diseminación en el personal de salud y la población.

\section{Desarrollo}

El médico anestesiólogo forma parte del personal de salud en mayor riesgo de contagio, ya que está expuesto al manejo de la vía aérea y los aerosoles emanados dentro y fuera de quirófano, por lo que debe contar con el equipo necesario, suficiente y de buena calidad para su protección, el cual es obligación del patrón, ya sea institucional o no, quien debe proporcionárselo al anestesiólogo, con el objetivo de salvaguardar la integridad del médico anestesiólogo y del personal de salud.

Lo anterior tiene fundamento legal en la Norma Oficial Mexicana NOM-170-SSA1-1998 para la Práctica de la Anestesiología en el punto 7.2 a $7.5^{1}$ donde hace mención de que «Los establecimientos prestadores de servicios de salud, para la práctica de la anestesiología, deberán contar con el equipo mínimo obligatorio para la práctica en condiciones razonables de seguridad», debiendo contar como mínimo con lo que menciona el Apéndice A de esta norma: «guantes especiales, cubrebocas con mica o lentes protectores oculares». La empresa o institución deberá contar además con el equipo de protección personal, con las instalaciones adecuadas para garantizar la seguridad de los trabajadores ${ }^{2}$ y más aún en enfermedades infectocontagiosas, ya que es obligación de la institución y del Estado garantizar la salud de todos sus gobernados (Artículo 4 Constitucional, Párrafo $\left.4^{\circ}\right) .^{3}$

De no cumplir con la normativa para evitar el riesgo de contagio en el personal de salud, el patrón estaría obligado a la indemnización del anestesiólogo en caso de contagio de COVID-19 de ser adquirido por motivo o en ejercicio de su

\footnotetext{
1 7.2 En la práctica de la anestesiología, será el responsable del establecimiento quien supervise la aplicación de la presente Norma Oficial en gabinetes de diagnóstico con la participación del médico anestesiólogo y con el equipamiento mínimo indispensable. 7.3 Los establecimientos prestadores de servicios de salud donde se realiza la práctica de la anestesiología, deberán contar con el equipo mínimo obligatorio para la práctica en condiciones razonables de seguridad y que se describen en el apéndice A.

7.4 Todo el equipo médico deberá estar sujeto a mantenimiento preventivo, correctivo y sustituido de acuerdo a los estándares obligatorios.

7.5 Independientemente del equipo listado, los establecimientos prestadores de servicios de salud donde se practique la anestesiología deberán contar con todo el equipo que se especifica en el apéndice A de la presente Norma Oficial Mexicana que se acota a continuación: equipo de protección para anestesiólogo en el manejo de pacientes infectocontagiosos (guantes especiales, cubreboca con mica, o lentes protectores oculares).

2 Artículo 123 constitucional apartado A fracciones XV. El patrón estará obligado a observar, de acuerdo con la naturaleza de su negociación, los preceptos legales sobre higiene y seguridad en las instalaciones de su establecimiento, y a adoptar las medidas adecuadas para prevenir accidentes en el uso de las máquinas, instrumentos y materiales de trabajo, así como a organizar de tal manera éste, que resulte la mayor garantía para la salud y la vida de los trabajadores, y del producto de la concepción, cuando se trate de mujeres embarazadas. Las leyes contendrán, al efecto, las sanciones procedentes en cada caso.

Ley Federal de trabajo. Artículo 475 Bis.- El patrón es responsable de la seguridad e higiene y de la prevención de los riesgos en el trabajo, conforme a las disposiciones de esta ley, sus reglamentos y las normas oficiales mexicanas aplicables. Es obligación de los trabajadores observar las medidas preventivas de seguridad e higiene que establecen los reglamentos y las normas oficiales mexicanas expedidas por las autoridades competentes, así como las que indiquen los patrones para la prevención de riesgos de trabajo.

${ }^{3}$ Artículo $4^{0}$ constitucional, párrafo 4to. que cita: «Toda persona tiene derecho a la protección de la salud».
} 
profesión ${ }^{4}$ así como sus complicaciones como la neumonía viral, que se especifica en la Ley Federal de Trabajo, Art. 512E. ${ }^{4}$

Asimismo, en caso de extrema urgencia de salud, el Presidente de la República deberá dictar las medidas necesarias para la preservación de la salud. ${ }^{5}$ Teniendo en cuenta que en estos casos los encargados directos de la atención de los pacientes deberán tener todas las medidas pertinentes necesarias ${ }^{6}$ para salvaguardar su salud y su vida en primera instancia para poder dar la atención indiscriminada a los pacientes y la preservación de la salud comunitaria. ${ }^{7}$

Por lo que se establece en la Ley General de Salud que el profesional de la salud, en este caso el anestesiólogo, deberá

\footnotetext{
$\overline{{ }^{4} \text { Artículo 512-E. La Secretaría del Trabajo y Previsión Social establecerá la coordi- }}$ nación necesaria con la Secretaría de Salud y con el Instituto Mexicano del Seguro Social para la elaboración de programas y el desarrollo de campañas tendientes a prevenir accidentes y enfermedades de trabajo. 136. Virosis (hepatitis, enterovirosis, rabia, psitacosis, neumonías a virus, mononucleosis infecciosa, poliomielitis y otras). ${ }^{5}$ Art. 73 fracción XVI 1a. El Consejo de Salubridad General dependerá directamente del Presidente de la República, sin intervención de ninguna Secretaría de Estado, y sus disposiciones generales serán obligatorias en el país. 2a. En caso de epidemias de carácter grave o peligro de invasión de enfermedades exóticas en el país, la Secretaría de Salud tendrá obligación de dictar inmediatamente las medidas preventivas indispensables, a reserva de ser después sancionadas por el Presidente de la República.

${ }^{6}$ Ley General de Salud. Artículo 142.

${ }^{7}$ Ley General de Salud. Art 10 Bis. El Personal médico y de enfermería que forme parte del Sistema Nacional de Salud, podrá ejercer la objeción de conciencia y excusarse de participar en la prestación de servicios que establece esta ley. Cuando se ponga en riesgo la vida del paciente o se trate de una urgencia médica, no podrá invocarse la objeción de conciencia, en caso contrario se incurrirá en la causal de responsabilidad profesional.
}

Artículo 27. Para los efectos del derecho a la protección de la salud, se considerarán servicios básicos de salud los referentes a: II. La prevención y el control de las enfermedades transmisibles de atención prioritaria.

Artículo 51. Los usuarios tendrán derecho a obtener prestaciones de salud oportunas y de calidad idónea y a recibir atención profesional y éticamente responsable, así como trato respetuoso y digno de los profesionales, técnicos y auxiliares.

Artículo 142. Los profesionales, técnicos y auxiliares de la salud, al tener conocimiento de un caso de enfermedad transmisible, están obligados a tomar las medidas necesarias, de acuerdo con la naturaleza y características del padecimiento, aplicando los recursos a su alcance para proteger la salud individual y colectiva.

${ }^{8}$ Ley General de Salud. Artículo 468. Al profesional, técnico o auxiliar de las disciplinas para la salud, que sin causa legítima se rehúse a desempeñar las funciones o servicios que solicite la autoridad sanitaria en ejercicio de la acción extraordinaria en materia de salubridad general, se le aplicará de seis meses a tres años de prisión y multa por el equivalente de cinco a cincuenta días de salario mínimo general vigente en la zona económica de que se trate.

Artículo 469. Al profesional, técnico o auxiliar de la atención médica que sin causa justificada se niegue a prestar asistencia a una persona, en caso de notoria urgencia, poniendo en peligro su vida, se le impondrá de seis meses a cinco años de prisión y multa de cinco a ciento veinticinco días de salario mínimo general vigente en la zona económica de que se trate y suspensión para ejercer la profesión hasta por dos años. Si produjere daño por la falta de intervención, podrá imponerse, además, suspensión definitiva para el ejercicio profesional, a juicio de la autoridad.

Código Penal del Distrito Federal Artículo 324. Se impondrán prisión de seis a doce años, de cien a trescientos días multa y suspensión para ejercer la profesión, por un tiempo igual al de la pena de prisión, al médico en ejercicio que: I. Estando en presencia de un lesionado o habiendo sido requerido para atender a éste, no lo atienda o no solicite el auxilio de la institución adecuada; o II. Se niegue a prestar asistencia a un enfermo cuando éste corra peligro de muerte o de una enfermedad o daño más grave y, por las circunstancias del caso, no pueda recurrir a otro médico ni a un servicio de salud. Si la víctima u ofendido de este delito es una niña, niño, menor de edad, adolescente o persona inimputable, incapaz, adulto mayor o integrante o miembro de una comunidad o pueblo indígena, las sanciones previstas en este artículo se triplicarán. dar la atención requerida o prestar auxilio si es solicitado por las autoridades sanitarias en ejercicio de acción extraordinaria, o si existe algún riesgo que ponga en peligro la vida del paciente con COVID-19. ${ }^{8}$ De no realizarlo competente a su profesión será motivo de sanción legal de no existir una causa que lo justifique.

\section{Conclusiones}

El manejo de pacientes infectados con COVID-19 en la actualidad representa una urgencia sanitaria, por lo que se colige que:

- Si bien es cierto, la obligación del profesional de la salud es la de otorgar el apoyo a la atención médica, sin discriminación a estos pacientes, y que en caso de no hacerlo podemos ser sancionados tanto administrativa como penalmente.

- Empero, por otro lado, no se debe dejar de atender que la institución (patrón) o bien, el Estado está obligado a otorgar todo el equipo de protección necesario para que el profesional de salud realice sus actividades y salvaguarde su vida, evitando cualquier riesgo de trabajo.

- Al ser la vida de la persona parte de los derechos fundamentales del hombre así como un Derecho Humano, reconocido tanto por la Constitución Política de los Estados Unidos Mexicanos como a nivel internacional, por medio del acatamiento a los Tratados Internacionales, como lo mandata el artículo 133 de este supremo ordenamiento legal, resulta que efectivamente, el médico sí está obligado a atender a los pacientes con COVID 19 en estado de gravedad y posible muerte, con la salvedad de que no debe dejar de observarse que la protección de su propia vida está por encima de cualquier acto profesional, por lo que siempre y en todo momento, sin excepción, deberá tener todas las medidas pertinentes para la protección de su integridad, y en este caso, por ende, la de su entorno.

\section{SALUD MENTAL E INTERVENCIÓN EN CRISIS DEL ANESTESIÓLOGO QUE ATIENDE PACIENTES CON SARS-COV2/COVID-19}

\author{
Mtra. en Psic. Adriana Carapia-Sadurni
}

La pandemia por SARS-CoV-2 (COVID-19) presenta un efecto estresante sin precedentes para los pacientes y los sistemas de atención médica en todo el mundo. Frente a esta situación, los trabajadores de la salud, quienes atienden de manera directa en el diagnóstico, tratamiento y cuidado de los pacientes con COVID-19 están en mayor riesgo de desarrollar estrés y otros síntomas que alteran la salud mental. 
Las respuestas psicológicas y conductuales adversas a los brotes de enfermedades infecciosas son comunes e incluyen insomnio, sentimientos de seguridad reducidos, mayor consumo de alcohol y tabaco, síntomas somáticos (síntomas físicos, como falta de energía, dolores y molestias generales). Sentimientos de vulnerabilidad o pérdida de control, preocupaciones sobre la salud de uno mismo, la propagación del virus, la salud de la familia y otros, cambios en el trabajo y el aislamiento.

En un estudio transversal de 1,257 trabajadores de la salud (493 médicos y 764 enfermeras) en 34 hospitales equipados con clínicas de fiebre o salas para pacientes con COVID-19 en múltiples regiones de China se encontró que 50.4\% informaron síntomas de depresión, 44.6\% informaron ansiedad, $34.0 \%$ tenían insomnio y $71.5 \%$ reportaron angustia.

Proteger a los trabajadores de la salud es un componente importante de las medidas de salud pública para abordar la epidemia de COVID-19. Las intervenciones especiales para promover el bienestar mental en los trabajadores de la salud expuestos a COVID-19 deben implementarse de inmediato, y las mujeres, las enfermeras y los trabajadores de primera línea requieren atención especial. Esto pone a los anestesiólogos, intensivistas y enfermeras en un riesgo significativo, lo cual hace que se incremente el estrés al que están sometidos de manera cotidiana.

Por ello es de suma importancia la asistencia psicológica a estos profesionales de manera cercana, la cual puede ser a través de llamadas telefónicas o bien por videollamada, con el fin de prestar atención a las posibles reacciones en situación de estrés intenso; algunas de las recomendaciones que se pueden realizar de manera inmediata y que pueden paliar las emociones son las siguientes:

Satisfaga las necesidades básicas: comer, dormir regularmente para optimizar su capacidad de cuidarse a sí mismo y a los demás.

Tome descansos: el descanso y las actividades relajantes pueden proporcionar una distracción útil.

Manténgase conectado: dar y recibir apoyo de familiares, amigos y colegas puede reducir los sentimientos de aislamiento.

Manténgase actualizado: confíe en fuentes confiables de información. Participe en reuniones de trabajo donde se proporciona información relevante.

Auto check-in: vigilarse a sí mismo en busca de signos de mayor estrés. Hable con un familiar, amigo, compañero o supervisor si es necesario.

Servicio de honor: recuérdese a usted mismo (y a otros) el importante trabajo que está haciendo. Reconozca a sus colegas por su servicio siempre que sea posible.
Prestar atención y expresión de sus emociones

Y no olvide que...

Somos humanos $y$, por tanto, nos podemos ver afectados emocionalmente de la misma manera que el resto de

personas

\section{RECOMENDACIONES PARA LA CONDUCTA A SEGUIR EN LA INTUBACIÓN TRAQUEAL EN PACIENTES ADULTOS CON COVID-19}

\section{Dra. Idoris Cordero-Escobar}

La intubación endotraqueal es en especial riesgosa en pacientes con COVID-19, dado el contacto cercano que tienen los profesionales de la salud con las vías respiratorias y las secreciones del paciente.

Por ello, la protección personal es una prioridad; antes de iniciar la intubación, debemos extremar las precauciones de aislamiento de la vía aérea y por contacto. Este equipo de protección personal (EPP) debe constar de: una mascarilla de alta eficacia (N95, FFP2 O FFP3), una protección ocular de armadura integral o un protector facial completo, un par de guantes, botas y una bata impermeable desechable. Para la intubación, el personal implicado debe estar entrenado en la adecuada colocación y retirada del equipo de protección personal. Para realizar la intubación se requieren dos personas: el que realiza la intubación y el ayudante que alcanzará el tubo endotraqueal una vez que confirmó el correcto funcionamiento del manguito neumotaponador, insuflará el mismo, realizará maniobras de Sellick en caso necesario y acoplará el tubo endotraqueal al circuito. Una vez terminada la intubación, recogerá en bolsa plástica el laringoscopio/videolaringoscopio y programará el ventilador.

En aquellos pacientes con COVID-19 que requieren intubación endotraqueal, sea para ventilación o para cualquier tipo de intervención quirúrgica, se recomienda que la realice el profesional más experimentado, buscando minimizar el número de intentos y el riesgo de transmisión de la enfermedad.

Hasta donde sabemos, el SARS-CoV-2 parece propagarse por grandes gotas respiratorias. Es probablemente un procedimiento generador de aerosol de partículas pequeñas (menos de $5 \mu \mathrm{m}$ ), lo que aumenta el riesgo de transmisión al intubador. $\mathrm{Si}$ la intubación es planificada, se debe realizar preoxigenación con oxígeno al $100 \%$, usando una mascarilla facial durante un período mínimo de cinco minutos.

Se recomienda seguir un protocolo de inducción de secuencia rápida con succinilcolina o con rocuronio. El asistente debe saber ejercer la presión cricoidea. Se sugiere evitar, si es posible, la ventilación manual antes de la intubación. Si fuera necesario, debemos realizarla con volúmenes corrientes bajos, a expensas de aumentar la frecuencia respiratoria. 
A menos que se considere imprescindible, debemos evitar la intubación en pacientes despiertos. Ante una vía aérea difícil, podemos considerar como dispositivo de intubación el videolaringoscopio. También podemos prever el uso de una guía de Eschmann.

Debemos valorar el uso de laringoscopía/videolaringoscopía desechable. En entornos donde la videolaringoscopía esté disponible y el personal sea experto, se sugiere utilizarlo en lugar de la laringoscopía directa para que, de esta manera, se maximicen las posibilidades de éxito. Se sabe que no todos los centros tienen acceso a videolaringoscopios o usuarios expertos, por lo que en esos casos se recomienda que esta indicación sea condicional.
Para recoger las secreciones del paciente, se debe rodear la cabeza con un paño. No debemos ventilar para no aumentar las presiones en las vías respiratorias y con ello provocar vómitos. Mientras esto sucede, el ayudante insuflará el manguito neumotaponador.

No se debe ventilar hasta que el circuito esté adaptado al tubo endotraqueal, así como no se recomienda no ventilar con presión positiva, ni emplear altos flujos si se utilizará ventilación mecánica no invasiva de alto flujo.

Cabe recordar que al término de la intubación, es necesario que retiremos cuidadosamente el EPP en un lugar predeterminado para esta cuestión.

Árbol de decisión para abordar la tráquea en pacientes adultos con COVID-19

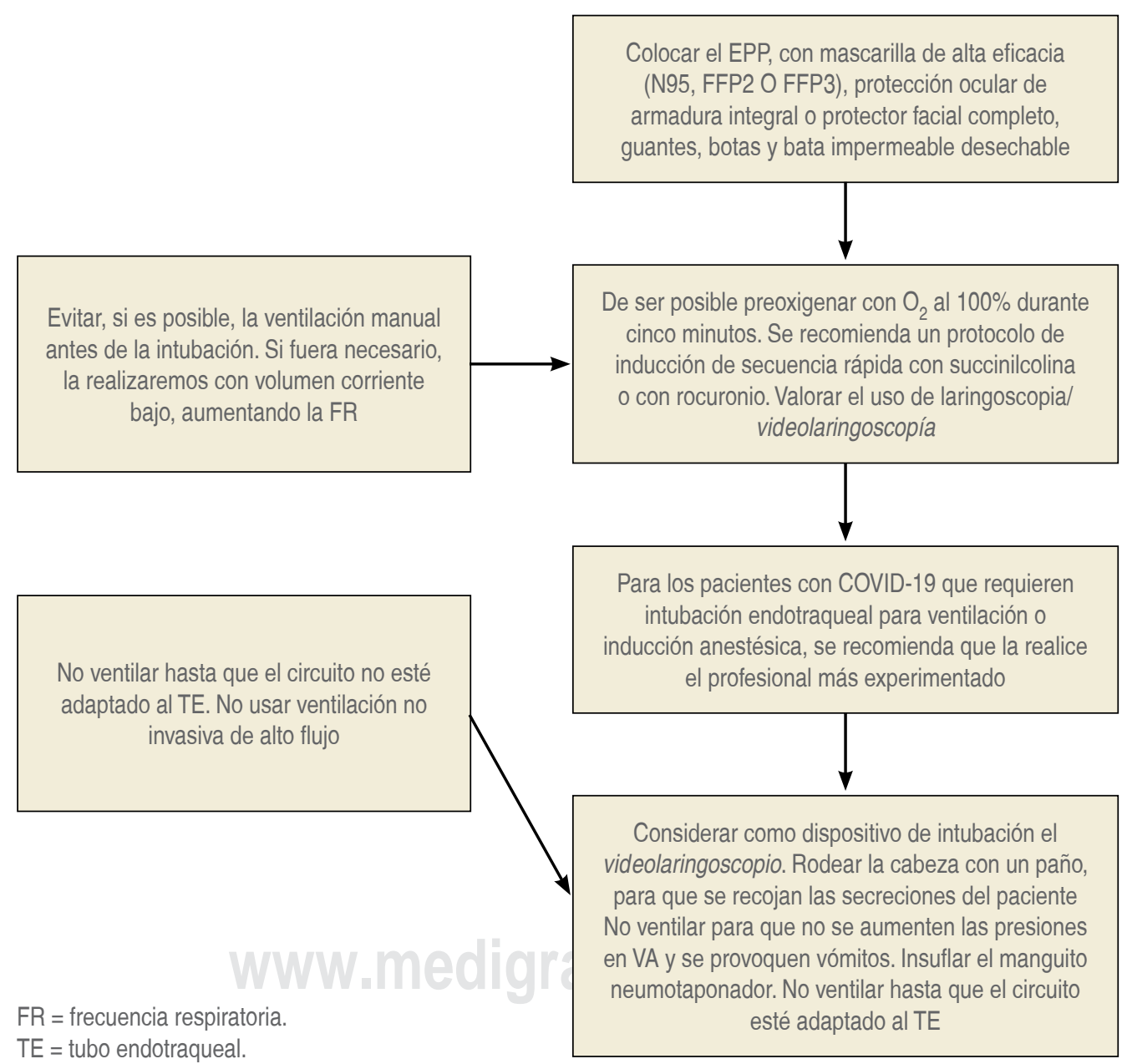




\section{BIBLIOGRAFÍA}

\section{- SARS-CoV-2/COVID-19 consideraciones generales}

- Huang C, Wang Y, Li X, Ren L, Zhao J, Hu Y, et al. Clinical features of patients infected with 2019 novel coronavirus in Wuhan, China. Lancet. 2020;395:497-506.

- https:/www.who.int/docs/default-source/coronaviruse/situationreports/20200401-sitrep-72-covid-19.pdf?sfvrsn=3dd8971b_2.

- https://coronavirus.gob.mx/datos/ [Información consultada 10 de mayo del 2020]).

- Tyrrell DAJ, Myint SH. Coronaviruses. In: Baron S, editor. Medical Microbiology. 4th ed. Galveston (TX): University of Texas Medical Branch at Galveston; 1996. Chapter 60. Disponible en: https://www. ncbi.nlm.nih.gov/books/NBK7782/.

- Vaduganathan M, Vardeny O, Michel T, McMurray J, Pfeffer S, Solomon S. Renin-angiotensin-aldosterone system inhibitors in patients with COVID-19. NEJM. 2020. doi: 10.1056/NEJMsr2005760.

- Li Q, Guan X, Wu P, et al. Early transmission dynamics in Wuhan, China, of novel coronavirus-infected pneumonia. N Engl J Med. 2020;382:1199-1207.

- Guan W, Ni Z, Hu Y, Liang W, Ou C, He J, et al. Clinical characteristics of coronavirus disease 2019 in China. N Engl J Med. doi: 10.1056/ NEJMoa2002032.

- Jin YH, Cai L, Cheng ZS, Cheng H, Deng T, Fan YP et al. A rapid advice guideline for the diagnosis and treatment of 2019 novel coronavirus (2019-nCoV) infected pneumonia (standard version). Mil Med Res. 2020;7:4. Available in: https://doi.org/10.1186/s40779020-0233-6.

- Lane HC, Marston HD, Fauci AS. Conducting clinical trials in outbreak settings: points to consider. Clin Trials. 2016;13:92-95.

\section{- Equipo de protección personal}

- Fowler RA, Guest CB, Lapinsky SE, Sibbald WJ, Louie M, Tang P, et al. Transmission of severe acute respiratory syndrome during intubation and mechanical ventilation. Am J Respir Crit Care Med. 2004;169:11981202. (Accessed 2010 Oct 29) Available: http://ajrccm.atsjournals.org/ cgi/reprint/169/11/1198.

- Tran K, Cimon K, Severn M, Pessoa-Silva CL, Conly J. Aerosol generating procedures and risk of transmission of acute respiratory infections to healthcare workers: a systematic review. PloS One. 2012;7:e35797.

- Raboud J, Shigayeva A, McGeer A, Bontovics E, Chapman M, Gravel $\mathrm{D}$, et al. Risk factors for SARS transmission from patients requiring intubation: a multicenter investigation in Toronto, Canada. PLoS One. 2010;5:e10717.

- Chen X, Liu Y, Gong Y, Guo X, Zuo M, et al. Perioperative management of patients infected with the novel coronavirus: Recommendation from the Joint Task Force of the Chinese Society of Anesthesiology and the Chinese Association of Anesthesiologists. Anesthesiology. 2020. https:// www.asahq.org/about-asa/newsroom/news-releases/2020/03/updatethe-use-of-personal-protective-equipment-by-anesthesia-professionalsduring-the-covid-19-pandemic.

- Centers for Disease Control and Prevention (CDC). Interim Infection Prevention and Control Recommendations for Patients with Suspected or Confirmed Coronavirus Disease 2019 (COVID-19) in Healthcare Settings. Updated March 10, 2020. [Accessed 22 March 2020].

- Centers for Disease Control and Prevention (CDC). Strategies for optimizing the supply of N95 respirators: crisis/alternate strategies. Updated March 17, 2020. [Accessed 22 March 2020].

- Centers for Disease Control and Prevention (CDC). Checklist for Healthcare Facilities: Strategies for Optimizing the Supply of N95 Respirators during the COVID-19 Response. Updated March 5, 2020. (Accessed 22 March 2020).

- Centers for Disease Control and Prevention (CDC). Recommended Guidance for Extended Use and Limited Reuse of N95 Filtering
Facepiece Respirators in Healthcare Settings. Updated March 28, 2018. [Accessed 22 March 2020].

- FDA Press Release: Coronavirus (COVID-19) Update: FDA and CDC take action to increase access to respirators, including N95s, for health care personnel. Updated March 2, 2020. [Accessed 22 March 2020].

- Canelli R, Connor CW, Gonzalez M, Nozari A, Ortega R. Barrier enclosure during endotracheal intubation. N Engl J Med. 2020; https:// doi.org/10.1056/NEJMc200758.

- Chan MT, Chow BK, Lo T, Ko FW, Ng SS, Gin T, et al. Exhaled air dispersion during bag-mask ventilation and sputum suctioningImplications for infection control. Scientific Reports. 2018;8:1-8. https:// doi.org/10.1038/s41598-017-18614-1.

- Fowler RA, Guest CB, Lapinsky SE, Sibbald WJ, Louie M, Tang P, et al. Transmission of severe acute respiratory syndrome during intubation and mechanical ventilation. Am J Respir Critl Care Med. 2004;169:1198-1202.

- Hsien YL. Aerosol Box. 2020; Retrieved from: https://sites.google.com/ view/aerosolbox/home?authuser $=0$.

- Madani A, Gallix B, Pugh CM, Azagury D, Bradley P, Fowler D, Aggarwal R. Evaluating the role of simulation in healthcare innovation: Recommendations of the Simnovate Medical Technologies Domain Group. BMJ Simulation and Technology Enhanced Learning. 2017;3:S8S14. https://doi.org/10.1136/bmjstel-2016-000178.

\section{- Manejo de la vía aérea en el paciente con COVID-19}

- Cook TM, El-Boghdadly K, McGuire B, McNarry AF, Patel A, Higgs A. Consensus guidelines for managing the airway in patients with COVID-19. Anaesthesia. 2020; doi: 10.1111/anae.15054.

- Lingzhong M, Qiu H, Wan L, Yuhang A, Xue Z, Guo Q, et al. Intubation and ventilation amid the COVID-19 outbreak: wuhan's experience. Anesthesiology. 2020; 10.1097/ALN.0000000000003296.

- Chen X, Liu Y, Gong Y, Guo X, Zuo M, et al. Perioperative management of patients infected with the novel coronavirus: recommendation from the joint task force of the Chinese Society of Anesthesiology and the Chinese Association of Anesthesiologists. Anesthesiology. 2020; 26;10.1097/ ALN.0000000000003301.

- Por qué posponer las cirugías electivas y no las urgentes o emergentes durante la pandemia de COVID-19

- Rajan N, Joshi GP. The COVID-19: Role of ambulatory surgery facilities in this global pandemic. Anesth Analg. 2020; PMID: 32243288. doi: 10.1213/ANE.0000000000004847.

- Besnier E, Tuech JJ, Schwarz L. We asked the experts: COVID-19 outbreak: Is there still a place for scheduled surgery? "Reflection from pathophysiological data”. World J Surg. 2020; PMID: 32246185. doi: 10.1007/s00268-020-05501-6.

- Lei S, Jiang F, Sua W, Chen C, Chen J, Mei W, et al. Clinical characteristics and outcomes of patients undergoing surgeries during the incubation period of COVID-19 infection. E Clinical Medicine. 2020;5:100331. PMID: 32292899. PMCID: PMC7128617. doi: 10.1016/j.eclinm.2020.100331.

- Liang W, Guan W, Chen R, Wang W, Li J, Xu K, et al. Cancer patients in SARS-CoV-2 infection: a nationwide analysis in China. Lancet Oncol. 2020;21:335-337. PMID: 32066541. PMCID: PMC7159000. doi: 10.1016/S1470-2045(20)30096-6.

- Xia LJ, Li W, Zhai JC, Yan CW, Chen JB, Yang H. Significance of neutrophil-to-lymphocyte ratio, platelet-to-lymphocyte ratio, lymphocyte-to-monocyte ratio and prognostic nutritional index for predicting clinical outcomes in T1-2 rectal cancer. BMC Cancer. 2020;20:208. PMID: 32164623. PMCID: PMC7066735. doi: 10.1186/ s12885-020-6698-6. 
- Recomendaciones para cirujanos ante la pandemia de COVID-19

- Gobierno de España. Ministerio de Sanidad. Dirección General de salud pública, calidad e innovación. Centro de Coordinación de Alertas y Emergencias Sanitarias. Procedimiento de Actuación frente a casos de Infección por el nuevo coronavirus (SARS-CoV-2). (Actualizado a 11 de marzo de 2020).

- Shaoqing L, Fang J, Wating S, Chang C, Jingli C, Wei M, et al. Clinical characteristics and outcomes of patients undergoing surgeries during the incubation period of COVID-19 infection. E Clinical Medicine. 2020; https://doi.org/10.1016/j.eclinm.2020.100331.

- Gu J, Han B, Wang J. COVID-19: Gastrointestinal manifestations and potential fecal-oral transmission. Gastroenterology. 2020. pii: S00165085(20)30281-X. doi: 10.1053/j.gastro.2020.02.054.

- Guan W, Ni Z, Hu Y, Liang W, Ou C, He J, et al. Clinical characteristics of coronavirus disease 2019 in China. N Engl J Med. 2020; 10.1056/ NEJMoa2002032.

- Kwak HD, Kim SH, Seo YS, Song KJ. Detecting hepatitis B virus in surgical smoke emitted during laparoscopic surgery. Occup Environ Med. 2016;73:857-863.

- COVID 19: Considerations for Optimum Surgeon Protection Before, During, and After Operation. American College of Surgeons 2020. https://www.facs.org/-/media/files/covid19/considerations_optimum_ surgeon_protection.ashx.

- Romaguera R, Cruz-González I, Ojeda S, Jiménez-Candil J, Calvo D, García SJ, et al. Consensus document of the Interventional Cardiology and Heart Rhythm Associations of the Spanish Society of Cardiology on the management of invasive cardiac procedure rooms during the COVID-19 coronavirus outbreak. REC Interv Cardiol. 2020.

- Updated Intercollegiate General Surgery Guidance on COVID-19. Royal College of Surgeons 2020; https://www.rcseng.ac.uk/coronavirus/jointguidance-for-surgeons-v2.

- Resources for smoke and gas evacuation during open, laparoscopic, and endoscopic procedures. 2020 by SAGES Webmaster. https://www. sages.org/resources-smoke-gas-evacuation-during-open-laparoscopicendoscopic-procedures.

- COVID-19. Elective Surgical Procedure Guidance: http://www.dph. illinois.gov/topics-services/diseases-and-conditions/diseases-a-z-list/ coronavirus/health-care-providers/elective-procedures-guidance.

- Kwak HD, Kim SH, Seo YS, Song KJ. Detecting hepatitis B virus in surgical smoke emitted during laparoscopic surgery. Occup Environ Med. 2016;73:857-863.

\section{- Anestesia regional en los pacientes con SARS-CoV-2/COVID-19}

- Chen R, Zhang Y, Huang L, Cheng B, Xia Z, Meng Q. Safety and efficacy of different anesthetic regimens for parturients with COVID-19 undergoing Cesarean delivery: a case series of 17 patients. Can J Anesth. 2020. PMID: 32180175. PMCID: PMC7090434. doi: 10.1007/s12630020-01630-7.

- Xia H, Zhao S, Wu Z, Luo W, Zhou C, Chen X. Emergency Caesarean delivery in a patient with confirmed coronavirus disease 2019 under spinal anaesthesia. Br J Anaesth. 2020; PMID: 32192711. PMCID: PMC7118662. doi: 10.1016/j.bja.2020.02.016.

- Zhong Q, Liu YY, Luo Q, Zou YF, Jiang HX, Li H, et al. Spinal anaesthesia for patients with coronavirus disease 2019 and possible transmission rates in anaesthetists: retrospective, single centre, observational cohort study. Br J Anaesth. 2020. PMID: 32234250. doi: 10.1016/j.bja.2020.03.007.

- Lie SA, Wong SW, Wong LT, Wong TGL, Chong SY. Practical considerations for performing regional anesthesia: lessons learned from the COVID-19 pandemic. Can J Anesth. 2020; PMID: 32212103. PMCID: PMC7095295. doi: 10.1007/s12630-020-01637-0.

\section{- Anestesia en pacientes embarazadas con SARS-CoV-2/COVID-19}

- Interim Considerations for Obstetric Anesthesia Care related to COVID19: Society for Obstetric Anesthesia and Perinatology; 2020 [Cited 15 April 2020 cuando se realiza esta revisión] Se encuentra disponible y reactualizándose. Available from: https://soap.org/ education/provider-education/expert-summaries/interim-considerationsfor-obstetric-anesthesia-care-related-to-covid19/.

- Chen R, Zhang Y, Huang L, Cheng BH, Xia ZY, Meng QT. Safety and efficacy of different anesthetic regimens for parturients with COVID-19 undergoing Cesarean delivery: a case series of 17 patients. Can J Anaesth. 2020. doi: 10.1007/s12630-020-01630-7.

- Brownfoot FC, Gagliardi DI, Bain E, Middleton P, Crowther CA. Different corticosteroids and regimens for accelerating fetal lung maturation for women at risk of preterm birth. Cochrane Database Syst Rev. 2013;(8):CD006764. doi: 10.1002/14651858.CD006764.

- Protocolo Coronavirus (COVID-19) y gestación embarazo versión 55/4/2020 [Cited 2020 March 29]. Disponible en: https://medicinafetalbarcelona.org/ protocolos/es/patologiamaternaobstetrica/covid19-embarazo.html.

- Favre G, Pomar L, Qi X, Nielsen-Saines K, Musso D, Baud D. Guidelines for pregnant women with suspected SARS-CoV-2 infection. Lancet Infect Dis. 2020. doi: 10.1016/s1473 3099(20)30157-2.

- Ksiezakowska K, Laszczyk M, Wilczynski J, Nowakowska D. SARSCoV infection and pregnancy. Ginekol Pol. 2008;79:47-50.

- Liu D, Li L, Wu X, Zheng D, Wang J, Yang L, et al. Pregnancy and perinatal outcomes of women with coronavirus disease (COVID-19) pneumonia: a preliminary analysis. AJR Am J Roentgenol. 2020:1-6. doi: 10.2214/AJR.20.23072.

- Lineamiento para la atención de pacientes por COVID-2019: 14 de febrero de 2020. Secretaría de Salud; 2020 https://www.cecyt3.ipn.mx/ banner/Lineamiento clinico COVID-19 CCINSHAE.pdf.

- Mullins E, Evans D, Viner RM, O’Brien P, Morris E. Coronavirus in pregnancy and delivery rapid review. Ultrasound Obst Gynecol. 2020. doi: 10.1002/uog.22014.

- Manejo de la mujer embarazada y el recién nacido con COVID-19 Sociedad Española de Ginecología y Obstetricia; 2020 [Citado 29 Marzo 2020]. https:// www.mscbs.gob.es/profesionales/saludPublica/ccayes/alertasActual/nCovChina/documentos/Documento_manejo_embarazo_recien_nacido.pdf.

- Society for Maternal-Fetal Medicine and Society for Obstetric and Anesthesia and Perinatology Labor and Delivery COVID-19 Considerations. https://s3.amazonaws.com/cdn.smfm.org/ media/2277/SMFMSOAP_COVID_LD_Considerations_3-27-20_ (final)_PDF.pdf.

\section{- Anestesia en pacientes pediátricos con SARS-CoV-2/COVID-19}

- Dong Y, Mo X, Hu Y, Qi X, Jiang F, Jiang F, Tong S. Epidemiological characteristics of 2143 pediatric patients with 2019 coronavirus disease in China. Pediatrics. 2020. doi: 10.1542/peds.2020-0702.

- Matava CT, Kovatsis PG, Summers JL. Castro P, Denning S, Yu J. et al. Pediatric airway management in Covid-19 patients - Consensus Guidelines from the Society for Pediatric Anesthesia's Pediatric Difficult intubation collaborative and the Canadian Pediatric Anesthesia Society. Anesthesia \& Analgesia. 2020. doi: 10.1213/ ANE.0000000000004872.

Sanz MH, Ferreras R, Sánchez A, Prada GM, Gálvez I, Fernández MI, et al. Documento consenso recomendaciones anestesia pediátrica sección anestesia pediátrica https://www.sedar.es/images/site/NOTICIAS/ coronavirus/2020_Ped_Covid19_recomendaciones_final.pdf.

- Uppal A, Sondekoppam RV, Lobo CA, Kolli S, Kalagara H. Practice recommendations on neuraxial anesthesia and peripheral nerve blocks during the COVID-19 pandemic A joint statement by the American Society of Regional Anesthesia and pain medicine (ASRA) and european society of regional anesthesia and pain therapy (esra) ASRA/ESRA COVID-19 Guidance for Regional Anesthesia (March 31 2020). 


\section{- Anestesia en pacientes oncológicos con SARS-CoV-2/COVID-19}

- Passaro A, Peters S, Mok TSK, Attili I, Mitsudomi T, de Marinis F, Testing for COVID-19 in lung cancer patients. Ann Oncol. 2020. doi: https://doi.org/10.1016/ j.annonc.2020.04.002.

- World Health Organization, Coronavirus Disease 2019 (COVID19) Situation Report 87. (16 April 2020) retrieved from: https://www.who. int/docs/default-source/coronaviruse/situation-reports/20200416-sitrep87-covid-19.pdf?sfvrsn=9523115a_2.

- The Lancet Oncology. COVID-19: global consequences for oncology. Lancet Oncol. 2020;21:467. doi: 10.1016/S1470-2045(20)30175-3.

- Desai A, Sachdeva S, Parekh T, Desai R. COVID-19 and cancer: lessons from a pooled meta-analysis. JCO Glob Oncol. 2020;6:557-559. doi: 10.1200/GO.20.00097.

- American society of clinical oncology. ASCO: COVID-19 Patient Care Information [Internet]. [Consultado abril 2020]. Disponible en: https:// www.asco.org/asco-coronavirus-information/care-individuals-cancerduring-covid-19.

- Liang W, Guan W, Chen R, et al: Cancer patients in SARS-CoV-2 infection: A nationwide analysis in China. Lancet Oncol. 2020;21:335337.

- Kim R. Effects of surgery and anesthetic choice on immunosuppression and cancer recurrence. J Transl Med. 2018;16:8. https://doi.org/10.1186/ s12967-018-1389-7.

- ASCO 2020, COVID 19 patient care information, Cancer Type Especific Guidance, retrieved from: https://www.asco.org/asco-coronavirusinformation/care-individuals-cancer-during-covid-19.

- ESMO 2020, Guidelines, Cancer Patient Management During the COVID 19 Pandemic, retrieved from: https://www.esmo. org/guidelines/cancer-patient-management-during-the-covid-19pandemic?page $=1$.

- Goh WJ, Tan QY, Lie Z, Tay SA, Ng YC. Preparing for a COVID-19 pandemic: a review of operating room outbreak response measures in a large tertiary hospital in Singapore. Canadian Journal of Anesthesia. 2020. https://doi.org/10.1007/s12630-020-01620-9.

- Balibrea JM, Badia JM, Rubio PI, Martín AE, Álvarez PE, García BS, et al Manejo quirúrgico de pacientes con infección por COVID-19. Recomendaciones de la Asociación Española de Cirujanos. Cirugía Española. 2020;1-9. https://doi.org/10.1016/j.ciresp.2020.03.001.

- Montero A, Maseda E, Bartolomé A, Aguilar R, González de Castro G, Gómez-Herreras R, et al. Practical recommendations for the perioperative management of the patient with suspection or serious infection by coronavirus SARS-CoV. Rev Esp Anest Reanim. 2020. https://doi.org/10.1016/j.redar.2020.03.003.

- Lie SA, Wong SW, Wong LT, Wong TGL, Chong SY. Practical considerations for performing regional anesthesia: lessons learned from the COVID-19 pandemic. Can J Anesth. 2020. doi: 10.1007/s12630020-01637-0.

- Bartlett DL Howe JR, Chang G, et al. Management of Cancer Surgery Cases During the COVID-19. Ann Surg Oncol. 2020. https://doi. org/10.1245/s10434-020-08461-2.

\section{- Anestesia en pacientes cardiópatas con SARS-CoV-2/COVID-19}

- He H, Zhao S, Han L, Wang Q, Xia H, Huang X, et al. Anesthetic management of patients undergoing aortic dissection repair with suspected severe acute respiratory syndrome coronavirus-2 infection. J Cardiothorac Vasc Anesth. 2020. doi: https://doi.org/10.1053/j. jvca.2020.03.021.

- Augoustides JG. Extracorporeal membrane oxygenation-crucial considerations during the coronavirus crisis. Journal of Cardiothoracic and Vascular Anesthesia. 2020. doi: https://doi.org/10.1053/j. jvca.2020.03.060.

- Augoustides JG. Cardiovascular Consequences and Considerations of Coronavirus Infection-perspectives for the cardiothoracic anesthesiologist and intensivist during the coronavirus crisis. Journal of Cardiothoracic and Vascular Anesthesia. 2020; doi: https://doi. org/10.1053/j.jvca.2020.04.001.

- He Y, Wei J, Bian J, Guo K, Lu J, Mei W, et al. Chinese Society of Anesthesiology Expert Consensus on anesthetic management of cardiac surgical patients with suspected or confirmed coronavirus disease 2019. Journal of Cardiothoracic and Vascular Anesthesia. 2020. 1-5. Article in press.

- Haft JW, Atluri P, Alawadi G, Engelman D, Grant MC, Hassan A, et al. Adult cardiac and vascular surgery, adult cardiac surgery during the COVID-19 pandemic: a tiered patient triage guidance statement. Ann Thorac Surg. 2020. doi: https://doi.org/10.1016/j. athoracsur.2020.04.003.

- Alhazzani W, Hylander MM, Arabi YM, Loeb M, Gong MN, Fan E, et al. Surviving Sepsis Campaign: guidelines on the management of critically ill adults with Coronavirus Disease 2019 (COVID-19) European Society of Intensive Care Medicine and the Society of Critical Care Medicine. doi: 10.1007/s00134-020-06022-5.

- Anestesia en procedimientos endoscópicos en pacientes con SARS-CoV-2/COVID-19

- Thompson C, Shen L. Letter to the editor: COVID-19 in endoscopy: time to do more? Gastrointest Endosc. 2020.

- D’Amico F, Baumgart DC, Danese S, Peyrin-Biroulet L. Diarrhea during COVID-19 infection: pathogenesis, epidemiology, prevention and management. Clin Gastroenterol Hepatol. 2020. doi: https://doi. org/10.1016/j.cgh.2020.04.001.

- Philip M, Lakhtakia S, Aggarwal R, Madan K, Saraswat V, Makharia G. Joint Guidance from SGEI, ISG and INASL for Gastroenterologists and Gastrointestinal Endoscopist on the Prevention, Care and Management of patients with COVID-19. Journal of Clinical and Experimental Hepatology. doi: https://doi.org/10-1016/j.jceh.2020.04.001.

- Sultan S, Lim JK, Altayar O, Davitkov P, Feuerstein JD, Siddique SM, et al. AGA Institute rapid recommendations for gastrointestinal procedures during the COVID-19 pandemic. Gastroenterology. 2020. doi: https:// doi.org/10.1053/j.gastro.2020.03.072.

\section{- Sedación en pacientes con SARS-CoV-2/COVID-19}

- Zhang HF, Bo L, Lin Y, Li FX, Sun S, Lin HB, Meng L. Response of Chinese Anesthesiologists to the COVID-19 Outbreak. Anesthesiology. 2020.

- Sanz MA, Hernández-Tejedor A, García AE, Rivera JJ, de Molina Ortiz FJ, Camps AS, et al. Recomendaciones de "hacer" y "no hacer" en el tratamiento de los pacientes críticos ante la pandemia por coronavirus causante de COVID-19 de los Grupos de Trabajo de la Sociedad Española de Medicina Intensiva, Crítica y Unidades Coronarias (SEMICYUC). Medicina Intensiva. 2020.

- Zhou F, Yu T, Du R, Fan G, Liu Y, Liu Z, et al. Clinical course and risk factors for mortality of adult inpatients with COVID-19 in Wuhan, China: a retrospective cohort study. Lancet. 2020. doi: 10.1016/S01406736(20)30566-3.

- Porcalla A, Barshteyn N, Snyder S, Bhattacharya M. An innovative, collaborative and strategic approach to proactively evaluate and update drug interactions based on prescribing information of newly approved medicinal products. Ther Innov Regul Sci. 2017;51:780-786.

- Meng L, Qiu H, Wan L, Ai Y, Xue Z, Guo Q, et al. Intubation and Ventilation amid the COVID-19 Outbreak: Wuhan's Experience. Anesthesiology. 2020. doi: 10.1097/ALN.0000000000003296. Hayhurst CJ, Pandharipande PP, Hughes CG. Intensive Care Unit delirium. A review of diagnosis, prevention and treatment. Anesthesiology. 2016;125:1229-1241.

- Nikooie R, Neufeld KJ, Oh ES, Wilson LM, Zhang A, Robinson KA, et al. Antipsychotics for treating delirium in hospitalized adults: a systematic review. Ann Intern Med. 2019. doi: 10.7326/M19-1860. 
- Feijoo M, Maseda E, Bartolomé A, Aguilar G, González de Castro R, Gómez-Herreras JI, et al. Practical recommendations for the perioperative management of the patient with suspection or serious infection by coronavirus SARS-CoV. Rev Esp Anest Rean. 2020.

\section{- Traslado intrahospitalario del paciente con SARS-CoV-2/COVID-19}

- Montero FA, Maseda E, Adalia BR, Aguilar G, González de Castro R, Gómez-Herreras JI, et al. Recomendaciones prácticas para el manejo perioperatorio del paciente con sospecha o infección grave por coronavirus SARS.CoV-2. Revista Española de Anestesiología y Reanimación. 2020. Obtenido de: https://doi.org/10.1016/j. redar.2020.03.003.

- Calvo RC, García LM, De Ceano M, Tomás RJ, Baquero FA, Navarro ML, et al. Manejo clínico del COVID-19: unidades de cuidados intensivos. España: Gobierno de España. Ministerio de Sanidad. 2020.

- Mose BJ, Mose BJ, Rubio PI, Antona E, Álvarez PE, García BS, Álvarez GM, et al. Manejo quirúrgico de pacientes con infección por COVID-19. Recomendaciones de la Asociación Española de Cirujanos. Cirugía Española, 9. [17 de marzo de 2020]. Obtenido de: https://doi. org./10.1016/j.ciresp.2020.03.001.

- Ti LK, Ang LS, Foong TW, Wei BS. What we do when a COVID-19 patient needs an operation: operating room preparation and guidance. Can J Anesth. 2020. Obtained in: https://doi.org/10.1007/s12630-02001617-4.

- Liao X, Wang B, Kang Y. Novel coronavirus infection during the 20192020 epidemic: Preparing intensive care units-the experience in Sichuan Province, China. Intensive Care Med. 2020;360. Obtained in: http:// dx.doi.org/10.1007/s00134-020-05954-2.

- Castellanos AM. Uso de optimización de recursos. Plan de contingencia para los servicios de medicina intensiva frente a la pandemia COVID-19. Sociedad Españoa de Enfermería Intensiva y Unidades Coronarias. 2020;73: Obtenido de: https://www.semicyuc.org/covid19_files/ Plan_de_Contingencia_COVID-19.pdf.

- Bouadma LL. Severe SARS-CoV-2 infections: practical considerations and management strategy for intensivist. Intensive Care Med. 2020;46:579-582. doi: https://doi.org/10.1007/s00134-020-05967-x.

\section{- Reconvirtiendo el quirófano durante la pandemia de COVID-19}

- Offeddu V, Yung, CF, Low MSF, Tam CC. Effectiveness of masks and respirators against respiratory infections in healthcare workers: a systematic review and meta-analysis. Clin Infect Dis. 2017;65:19341942.

- Shaw LF, Chen IH, Chen CS, Wu HH, Lai LS, Chen YY, Wang FD. Factors influencing microbial colonies in the air of operating rooms. BMC Infect Dis. 2018;18:4.

- Cook TM. Personal protective equipment during the COVID-19 pandemica narrative review. Anaesthesia. 2020. doi: 10.1111/anae.15071.

- Ti LK, Ang LS, Foong TW. What we do when a COVID-19 patient needs an operation: operating room preparation and guidance. Can J Anesth. 2020; doi: org/10.1007/s12630-020-01617-4. Published online 06 March 2020.

- Sanitización de la máquina de anestesia durante la pandemia de COVID-19

- Anesthesia Safety Foundation. Anesthesia machine use, protection, and decontamination during COVID-19 pandemic. 2020.

- CLASA. Guías de seguridad intraoperatoria. Atención pacientes con enfermedad COVID-19. Versión 27.3.2020. 2020.

- Papel del anestesiólogo en la reorganización del quirófano durante la pandemia de COVID-19
- World Health Organization. Coronavirus disease (COVID-19) outbreak. https://www.who.int/emergencies/diseases/novel-coronavirus-2019. [Accessed January 30, 2020] \& https://www.who.int/publications-detail/ clinical-management-of-severe-acute-respiratory-infection-when-novelcoronavirus-(ncov)-infection-is-suspected (Actualización 28/01/2020Acceso el 08/02/2020).

- https://www.mscbs.gob.es/profesionales/saludPublica/ccayes/ alertasActual/nCov-China/documentos/Procedimiento_2019-nCoV.pdf (Actualización 06/02/2020 - Acceso el 08/02/2020).

- COVID-19: American Society of Anesthesiologists (ASA). Recommendations for Anesthesia Management https://www. sciencedirect.com/science/article/pii/S105307702030197X.

- ASA \& APSF https:// www.asahq.org/about-asa/governance-andcommittees/asa-committees/committee-on-occupational-health/ coronavirus/clinical-faqs \& https://www.apsf.org/news-updates/ perioperative-considerations-for-the-2019-novel-coronavirus-covid-19/.

- Centers for Disease Control and Prevention. Coronavirus disease 2019 (COVID-19). https://www.cdc.gov/coronavirus/2019-ncov/index.html. [Accessed January 30, 2020].

- Zhao S, Ling K, Yan H, Zhong L, Peng X, Yao S, Huang J, Chen X. Anesthetic management of patients with COVID 19 infections during emergency procedures. J Cardiothorac Vasc Anesth. 2020;34:1125-1131. doi: 10.1053/j.jvca.2020.02.039. Epub 2020 Feb 28.

- Huang C, Wang Y, Li X, Ren L, Zhao J, Hu Y, et al. Clinical features of patients infected with 2019 novel coronavirus in Wuhan, China. Lancet. 2020;395:497-506.

- Radonovich LJ, Simberkoff MS, Bessesen MT et al. N95 respirators vs medical masks for preventing influenza among health care personnel: a randomized clinical trial. JAMA. 2019;322: 824-833.

- Implicaciones bioéticas en anestesiología durante la pandemia de COVID-19

- Andersen KG, Rambaut A, Lipkin WI, Holmes EC, Garry RF. The proximal origin of SARS-CoV-2. Nature Medicine. 2020;26:450-452. doi 10.1038/s41591-020-0820-9.

- Molina C, Moya D, Molina P, Astudillo Y, Morales A. COVID-19. Emergencia y emergentes: desafíos éticos de la investigación y atención desde los contextos del Sur. Práctica Familiar Rural. 2020;5: doi: /10.23936/pfr.v5i1.151.

- Ley General de Salud. Artículos LGS a 100, 323 y 324.

- Ley general de salud Cd Mx publicada el 7 de enero de 2008. Actualización el 27-08-2012.

- Implicaciones legales en la atención y manejo anestésico de pacientes con COVID-19

- Norma Oficial Mexicana NOM-170-SSA1-1998, Para la Practica de la Anestesiología.

- Constitución Política de los Estados Unidos Mexicanos.

- Ley Federal de Trabajo.

- Ley General de Salud.

- Secretaría del Trabajo y Previsión Social.

- Consejo de Salubridad General.

- Tratados internacionales.

- Salud mental e intervención en crisis del anestesiólogo que atiende pacientes con SARS-CoV-2/COVID-19

- Organización Mundial de la Salud. Brote de enfermedad por Coronavirus (COVID-19). [Accedido 17 Abril 2020] Disponible en: https://www. who.int/es/emergencies/diseases/novel-coronavirus-2019.

- Jianbo L, Simeng M, Ying W, Zhongxiang C, Jianbo H, Wei N, et al. Factors associated with mental health outcomes among health care workers exposed to coronavirus disease 2019. JAMA Netw Open. 2020;3:e203976. doi: 10.1001/jamanetworkopen.2020.3976. 
- Chan-Yeung M. Severe acute respiratory syndrome (SARS) and healthcare workers. Int J Occup Environ Health. 2004;10:421-427. doi: 10.1179/oeh.2004.10.4.421

- Lee AM, Wong JG, McAlonan GM, Cheung V, Cheung C, Sham PC, et al. Stress and psychological distress among SARS survivors 1 year after the outbreak. Can J Psychiatry. 2007;52:233-240. doi: 10.1177/070674370705200405.

- Bai Y, Lin CC, Lin CY, Chen JY, Chue CM, Chou P. Survey of stress reactions among health care workers involved with the SARS outbreak. Psychiatr Serv. 2004;55:1055-1057. doi: 10.1176/appi.ps.55.9.1055.

- Maunder R, Hunter J, Vincent L, Bennett J, Peladeau N, Leszcz M, et al. The immediate psychological and occupational impact of the 2003 SARS outbreak in a teaching hospital. CMAJ. 2003;168:1245-1251.

- Wang D, Hu B, Hu C, Zhu F, Liu X, Zhang J, et al. Clinical Characteristics of 138 Hospitalized Patients With 2019 Novel Coronavirus-Infected Pneumonia in Wuhan, China. Journal of the American Medical Association. 2020. doi: 10.1001/jama.2020.1585.

- Zucco L, Levy N, Ketchandji D, Aziz M, Ramachandran SK. Consideraciones perioperatorias para el nuevo coronavirus 2019 (COVID-19). https://www.apsf.org/es/news-updates/consideracionesperioperatorias-para-el-nuevo-coronavirus-2019-covid-19/.

- Consejo General de la Psicología de España: El Colegio de Psicología de Navarra elabora una guía para psicólogos que atienden telefónicamente durante la pandemia del COVID-19. [Accedido 16 Abril 2020] http:// www.infocop.es/view_article.asp?id=8688.

- Consejo General de la Psicología de España: Decálogo de Recomendaciones para profesionales del ámbito sanitario para un afrontamiento psicológico eficaz ante el malestar generado por el brote de Coronavirus-COVID-19. [Accedido 16 Abril 2020] http://www. infocop.es/view_article.asp?id=8678

- Recomendaciones para la conducta a seguir en la intubación traqueal en pacientes adultos con COVID-19

- Confederación Latinoamericana de Sociedades de Anestesiología (CLASA) [sitio web]. Protocolo COVID-19 [consultado: 20 de marzo de 2020]. http://anestesiaclasa.org/guia-pacientes-covid-19/.
- Aranda F, Aliste J, Altermatt F, Alvarez JP, Bernucci F, Bruhn A. Recomendaciones para el manejo de pacientes con COVID-19 con indicación terapéutica de ventilación mecánica que eventualmente son conectados a máquinas de anestesia Rev Chil Anest 2020:3;49 DOI: 10.25237/revchilanestv49n03.09

- American Society of Anesthesiologists ASA y la Anesthesia Patient Safety Foundation APSF [sitio web]. Guía APSF/ASA sobre el uso de las máquinas de anestesia como ventiladores de UCI Documento original en inglés. [consultado: 20 abril de 2020]. https://www.asahq. org/in-the-spotlight/coronavirus-covid-19-information/purposinganesthesia-machines-for-ventilators.

- World Health Organization. Statement on the second meeting of the International Health. Regulations. Emergency Committee regarding the outbreak of novel coronavirus (2019-nCoV) [sitio web]. 2020 [consultado: 22 de marzo de 2020]. https://www. who.int/newsroom/detail/30-01-2020-statement-on-the-secondmeeting-of-theinternational-health-regulations-(2005)-emergencycommitteeregarding-the-outbreak-ofnovel-coronavirus-(2019-ncov).

- Sociedad Española de Anestesiología y Reanimación (SEDAR). Recomendaciones para el manejo de la vía aérea en pacientes infectados por coronavirus [monografía en Internet]. 2020. [consultado 1 de mayo 2020]. Manejo-vía-aérea-paciente-con-coronavirus-SEDAR.pdf.

- Dirección General de Salud Pública, Calidad y Consumo de España [sitio web.] Información científica-técnica. Enfermedad por coronavirus, COVID-19. Actualización 4 abril 2020. [Consultado: 25 de abril de 2020]. https://www.mscbs.gob.es/profesionales/saludPublica/ccayes/ alertasActual/nCov-China/documentos/20200404_ITCoronavirus.pdf.

- Herman JA, Urits I, Kaye AD. COVID-19: general anesthesia precautions. J Clinical Anesth. 2020. doi.org/10.1016/j.jclinane.2020.109840.

- Aranda F, Aliste J, Altermatt F, Alvarez JP, Bernucci F, Cabrera MC. Recomendaciones para el manejo de pacientes con COVId19 en el perioperatorio. Rev Chil Anest. 2020;49:196-202. doi. org/10.25237/ revchilanestv49n02.03

- Wax RS, Christian MD. Practical recommendations for critical care and anesthesiology teams caring for novel coronavirus (2019-nCoV) patients. Can J Anesth. 2020;67:568-576. doi.org/10.1007/s12630020-. 